\title{
Subduction zone decoupling/retreat modelling explains south Tibet (Xigaze) and other supra-subduction zone ophiolites and their UHP mineral phases
}

Jared P. Butler ${ }^{1}$ and Christopher Beaumont ${ }^{1}$

\section{Keywords}

Tectonics; forearc ophiolites; subduction; geodynamic modeling; Himalaya-Tibet; UHP metamorphism

\begin{abstract}
The plate tectonic setting in which proto-ophiolite 'oceanic' lithosphere is created remains controversial with a number of environments suggested. Recent opinions tend to coalesce around supra-subduction zone (SSZ) forearc extension, with a popular conceptual model in which the proto-ophiolite forms during foundering of oceanic lithosphere at the time of
\end{abstract}


spontaneous or induced onset of subduction. This mechanism is favored in intra-oceanic settings where the subducting lithosphere is old and the upper plate is young and thin. We investigate an alternative mechanism; namely, decoupling of the subducting oceanic lithosphere in the forearc of an active continental margin, followed by subduction zone (trench) retreat and creation of a forearc oceanic rift basin, containing proto-ophiolite lithosphere, between the continental margin and the retreating subduction zone. A template of 2D numerical model experiments examines the trade-off between strength of viscous coupling in the lithospheric subduction channel and net slab pull of the subducting lithosphere. Three tectonic styles are observed: 1) C, continuous subduction without forearc decoupling; 2) R, forearc decoupling followed by rapid subduction zone retreat; 3 ) B, breakoff of subducting lithosphere followed by re-initiation of subduction and in some cases, forearc decoupling (B-R). In one case (BA-B-R; where BA denotes backarc) subduction zone retreat follows backarc rifting. Subduction zone decoupling is analysed using frictional-plastic yield theory and the Stefan solution for the separation of plates containing a viscous fluid. The numerical model results are used to explain the formation of Xigaze group ophiolites, southern Tibet, which formed in the Lhasa terrane forearc, likely following earlier subduction and not necessarily during subduction initiation. Either there was normal coupled subduction before subduction zone decoupling, or precursor slab breakoff, subduction re-initiation and then decoupling. Rapid deep upper-mantle circulation in the models during subduction zone retreat can exhume and emplace material in the forearc proto-ophiolite from as deep as the mantle transition zone, thereby explaining diamonds and other 10-15 GPa UHP phases in Tibetan ophiolites.

\section{Introduction}

Ophiolites represent on-land exposures of oceanic lithosphere, many but not all of which have been detached and tectonically emplaced onto continental plate margins (Dewey and Bird, 1971; Anonymous, 1972; Dilek and Furnes, 2011, 2014). Although they may form in a variety of tectonic environments, many ophiolites appear to have been created within a supra-subduction zone (SSZ) setting, by the extension and rifting of either a forearc, or intra-arc region above subducting oceanic lithosphere (Pearce et al., 1984; Shervais, 2001; 
Pearce, 2003; Metcalf and Shervais, 2008; Whattam and Stern, 2011; Dilek and Furnes, 2014).

An increasing number of SSZ ophiolites are thought to have formed in a forearc setting during the initiation of a new subduction zone, an interpretation made by analogy with the more recent Izu-Bonin-Mariana (IBM) forearc - inferred to have undergone subduction initiation 52 Ma (Stern and Bloomer, 1992; Metcalf and Shervais, 2008; Dilek and Furnes, 2009; Reagan et al., 2010; Stern et al., 2012). The hallmark of these 'subduction initiation ophiolites' is a distinct evolution in the composition of proto-ophiolite crust, whereby early MORB-like rocks with "distinct $\mathrm{Ti} / \mathrm{V}$ and $\mathrm{Yb} / \mathrm{V}$ ratios reflecting a greater depletion in moderately incompatible elements" (the 'Forearc basalts' of Reagan et al., 2010) give way to arc tholeiites and boninites, a trend reflecting increasing input of subducting slab-derived fluids and enhanced depletion of the mantle wedge (Dilek and Furnes, 2009; Stern et al., 2012; Pearce, 2014). This interpretation is often linked to a model in which spontaneous foundering of old oceanic lithosphere at a fracture zone leads to the gradual formation of a new subduction zone, and hence progressively increasing input of slab-derived fluids (Stern and Bloomer, 1992; Stern, 2004; Metcalf and Shervais, 2008).

Spontaneous subduction initiation may operate when coupling between the upper and lower plates is weak, e.g. a ridge-transform boundary where the upper plate comprises thin young oceanic lithosphere (Stern, 2004). However, it is less likely at rifted continental margins, where the stiffness of thick/cool lithosphere will resist bending (Gurnis et al., 2004). We present 2D thermomechanical models that are used to explore an alternative geodynamical model, that of subduction zone decoupling and forearc spreading at an active continental margin, an application of Royden (1993) concepts to active continental margins. It is not our intention to investigate whether spontaneous or induced subduction initiation (Hall et al., 2003; Stern, 2004; Nikolaeva et al., 2010; Baes et al., 2011) operates when the upper plate is continental, nor to present a general review of subduction modeling and over-riding plate dynamics, which is comprehensively reviewed by Gerya (2011). Instead, we focus on what controls subduction zone decoupling and subsequent forearc spreading, and demonstrate that forearc proto-ophiolitic crust with subduction initiation signatures likely forms in tectonic settings other than subduction initiation. 
We first present key results from a set of numerical experiments that demonstrate behaviors ranging from normal coupled subduction, to subduction zone decoupling and 'proto-ophiolite' formation (where we mean oceanic-like lithosphere that is later tectonically emplaced as an ophiolite), to subducting slab breakoff. This is followed by a discussion of the sensitivity of the models to the effective slab pull force and interplate coupling. We then compare the model results with the predictions of a basic theoretical analysis to develop a greater understanding of the model decoupling behavior.

We conclude with a discussion of the models in the context of south Tibetan ophiolites, particularly the Xigaze ophiolite, where mounting evidence points to formation in a forearc setting adjacent the Lhasa terrane during a hiatus in arc magmatism (Dai et al., 2013; An et al., 2014; Huang et al., 2015; Maffione et al., 2015; Xiong et al., 2016). Rather than being intrinsically related to subduction zone initiation per se, we suggest that forearc proto-ophiolite genesis at active continental margins is the product of subduction zone decoupling and subduction zone/trench retreat.

\section{Methods}

\subsection{Model design}

We use the 2D finite element software SOPALE-nested to solve thermomechanical creeping flows at the mantle scale (Fullsack, 1995; Beaumont et al., 2009; Appendix A1). The starting model geometry (Fig. 1; Table 1) represents a simplified active continental margin subduction system comprising oceanic pro-lithosphere and continental retro-lithosphere, overlying upper mantle, base $660 \mathrm{~km}$, and lower mantle, base $1200 \mathrm{~km}$. The oceanic lithosphere is $100 \mathrm{~km}$ thick, corresponding to a thermally-old ( 100 Myr) lithosphere, and comprises $3 \mathrm{~km}$ sediment, $6 \mathrm{~km}$ oceanic crust, and $91 \mathrm{~km}$ lithospheric mantle. The 120-km thick retro-continent comprises an upper 10-km thick weak layer, $14 \mathrm{~km}$ normal upper crust, $12 \mathrm{~km}$ lower crust, and $84 \mathrm{~km}$ lithospheric mantle. A small oceanic sediment accretionary wedge separates the oceanic and continental lithospheres and is underlain by a thin dipping layer of weak oceanic crust that serves as a guide during subduction initiation.

Model materials deform by either frictional-plastic (brittle) or power-law viscous (ductile) flows that include the effects of strain-softening/strain-weakening, respectively. At high stress, a saturation stress approximation to the Peierls flow law modifies power- 
law flow. Frictional-plastic deformation depends on the dynamical pressure and effective angle of internal friction ( $\phi_{\text {eff }}$; hereafter simply $\phi$ ). For most model materials, $\phi$ varies from $15-2^{\circ},\left(15^{\circ}\right.$ is the initial effective angle of internal friction including pore fluid pressure, and $2^{\circ}$ is fully strain-softened material). Oceanic sediment is initially weaker, with $\phi=8-2^{\circ}$. The upper $10 \mathrm{~km}$ of retro-continent crust also has $\phi=8-2^{\circ}$. Strain-softening is achieved by linearly decreasing $\phi$ over the range of strain $\varepsilon=0.5-1.5$ (Appendix A1).

Viscous deformation is based on a small set of reliable, laboratory-derived flow laws (Table 1). Viscosity can also be scaled by a factor $f$, to represent materials stronger or weaker than a base flow law (Appendix A1; see justification in Butler et al. 2014). During viscous strain-weakening, the effective viscosity is linearly reduced by $\mathrm{W}_{\mathrm{s}}$ over the range of strain second invariant $\varepsilon=5-10$ (Table 1 , Appendix A1). The exception is the oceanic sediment, which does not strain weaken, but has $f$-values which vary among experiments. The difference in the range of strain for softening/weakening reflects faulting in brittle rocks at low strain, versus the need for larger viscous strains to produce grain-size reduction, mylonitization or other weakening mechanisms. Oceanic crust and continental lower crust have scaled dry Maryland diabase flow laws (DMD $\times f=0.1$ and 0.5 respectively; Mackwell et al. 1998). Retro-continent upper crust has a wet quartzite flow law (WQ $\times f=1$ and 5 in the upper $10 \mathrm{~km}$ and lower $14 \mathrm{~km}$ respectively; Gleason and Tullis, 1995). Sediment has a $\mathrm{WQ} \times f_{\text {sed }}$ flow law where $f_{\text {sed }}$ varies among model experiments (see below). Mantle has a wet olivine flow law (Karato and $\mathrm{Wu}, 1993)$ scaled to represent either sublithospheric mantle (WOL $\times f=2$ ) or dehydrated lithospheric mantle $(f=3$ and 10 for oceanic and continental lithospheres, respectively). Owing to considerable uncertainty in its rheology (e.g. Billen, 2010), we assume a constant lower mantle viscosity, $1 \times 10^{21} \mathrm{~Pa}$ s. The model domain has stress-free upper surface, and no-slip sides and base. Convergence is driven by pro-lithosphere boundary velocity, $\mathrm{V}_{\mathrm{P}}=5 \mathrm{~cm} \mathrm{a}^{-1}$, and retrolithosphere boundary velocity is 0 (Fig.1). A stationary retro-lithosphere is appropriate for our application to the Xigaze ophiolite where the Lhasa terrane was stationary, or nearly so, from $\sim 130 \mathrm{Ma}$ (Li et al., 2016). Free subduction models have been addressed by Capitanio et al. (2010). We also discuss the boundary tectonic forces on the lithospheres in the results. The boundary tectonic force acting on the retro-lithosphere shows the resistance required for it to remain stationary, or correspondingly its strength required to 
resist rifting. Thermal boundary conditions (Table 1) are: basal heat flux $21 \mathrm{~mW} \mathrm{~m}^{-2}, 0^{\circ} \mathrm{C}$ surface, and insulated side boundaries. Radioactive heat production, $A_{R}$, is respectively 1.5 , 0.4 , and $1.0 \mu \mathrm{W} \mathrm{m}{ }^{-3}$ for continental upper and lower crust and oceanic sediment, giving initial steady-state retro-continent Moho temperature of $600^{\circ} \mathrm{C}$, and $62 \mathrm{~mW} \mathrm{~m}^{-2}$ surface heat flow.

Crustal materials undergo reversible pressure and temperature-dependent density changes at the eclogite and coesite-eclogite phase transitions (Appendix A1, Table 1). Basaltic oceanic crust (density $2950 \mathrm{~kg} \mathrm{~m}^{-3}$ ) transforms to eclogite (density $3400 \mathrm{~kg} \mathrm{~m}^{-3}$ ). Oceanic sediment transforms from a density of $2800 \mathrm{~kg} \mathrm{~m}^{-3}$ to $2900 \mathrm{~kg} \mathrm{~m}^{-3}$ and then 3370 $\mathrm{kg} \mathrm{m}^{-3}$ at HP and UHP conditions, respectively (Warren et al., 2008). Density reversal implies retrogression, not necessarily to the protolith, but to a material with the original density, e.g., eclogite to amphibolite (Warren et al., 2008). Mantle materials increase in density by $8 \%$ when crossing the $660-\mathrm{km}$ mantle boundary, a reversible phase change boundary with a Clapeyron slope of $-2 \mathrm{MPa} \mathrm{K}^{-1}$.

The dynamically consistent model topography is a product of the model calculation without any imposed constraints except for submarine water loading. For simplicity, the models do not include surface erosion or sediment deposition.

Model time is in millions of years, where 0 Myr corresponds to the state after 100 $\mathrm{km}$ of convergence during subduction initiation. The horizontal tectonic forces (total force - pressure) arising from velocity boundary conditions, slab pull, basal traction, and other forces acting on the lithospheres are monitored at the model boundaries.

\section{Model template and results}

\subsection{Experimental template}

In a set of 12 model experiments we tested the trade-off between to two key parameters, depletion density of the subducting oceanic lithospheric mantle, $\Delta \rho_{O L M}$, and viscous strength, $f_{\text {sed, }}$ of the subducting oceanic sediment. We explain why these are the key parameters in section 4.3.

The compositional density of the upper $51 \mathrm{~km}$ (i.e., depth $60 \mathrm{~km}$ ) of the model subducting oceanic lithospheric mantle $(O L M)$ is expressed in terms of its 'depletion' with respect to the underlying sub-lithospheric mantle (SLM), $\Delta \rho_{O L M}=\rho_{S L M}-\rho_{O L M}$. 'Depletion' 
measures this region's reduced compositional density owing to decompression melting/melt extraction when the oceanic lithosphere formed. Thermal expansion effects on density are similar for all models and are excluded from $\Delta \rho_{O L M}$. We tested $\Delta \rho_{O L M}$ values of 10 (minor melt extraction), 20, and 30 (moderate melt extraction) $\mathrm{kg} \mathrm{m}^{-3}$, where smaller $\Delta \rho_{O L M}$ increases slab pull and propensity for forearc decoupling. The values used for oceanic crustal thickness and density and for the thickness and density of the depleted lithospheric mantle correspond closely to Korenaga (2013, Fig. 9) for oceanic ridge decompression melting at a mantle potential temperature of $1350^{\circ} \mathrm{C}$. The assumed value of $\rho_{\mathrm{SLM}}=3300 \mathrm{~kg} \mathrm{~m}^{-3}$ (Korenaga, 2013, and Korenaga pers. comm.) which gives a depletion density 15-20 $\mathrm{kg} \mathrm{m}^{-3}$. The corresponding depletion density for the continental lithospheric mantle in our models is $30 \mathrm{~kg} \mathrm{~m}^{-3}$ and is constant for all models.

During convergence oceanic sediment subducts, forming a thin subduction channel beneath the forearc, and its viscous strength controls forearc decoupling. We tested $f_{\text {sed }}$ values $(0.1,0.3,0.5$ and 1$) \times W Q$.

We refer to the models by their two key properties, e.g., $\left(\Delta \rho_{O L M}=10\left(\mathrm{~kg} \mathrm{~m}^{-3}\right) ; f_{\text {sed }}=\right.$ 0.3). Models exhibit one of three main behaviors (summary Fig. 2):

1. C; coupled subduction, no subduction zone decoupling and no forearc spreading; 2. R; decoupling of the subduction zone, followed by subduction zone retreat, leading to forearc oceanic basin spreading and proto-ophiolite formation;

3.B; coupled subduction, shallow slab break-off, and re-initiation of subduction, in one model leading to subduction zone decoupling (B-R) as in behavior 2 .

We describe representative models exhibiting each behavior, and discuss the sensitivity of the models to $\Delta \rho_{O L M}$ and $f_{\text {sed. }}$.

\subsection{Model FA-C: coupled subduction}

Model FA-C $\left(\Delta \rho_{O L M}=30 ; f_{\text {sed }}=0.5\right.$; Fig. 3$)$ has medium lithospheric coupling and moderately depleted oceanic lithosphere resulting in low slab pull. Following an initial tectonically compressive phase $\left(F_{P} \sim-3000 \mathrm{GN} \mathrm{m}^{-1}\right.$; negative force indicates compression) with relatively shallow angle subduction (Fig. 3a; 3 Myr), the slab force becomes tensile (slab pull) and increases, and the subduction trajectory steepens (Fig.3b, d; 6.5 Myr). The pro-lithosphere net tensile force continues to increase, reaching $\sim 2800 \mathrm{GN} \mathrm{m}^{-1}$ as the slab approaches the base of the upper mantle (Fig 3d; 10.5 Myr). Subducted oceanic sediment 
has formed a thin channel between the oceanic and continental lithospheres, but is sufficiently strong that the two plates remain coupled (Fig. 3 inset panels, yellow). As the slab enters the more viscous lower mantle (Fig. 3c; $15.5 \mathrm{Myr}$ ) the net tensional force resulting from slab pull gradually decreases from its maximum of $\sim 3700 \mathrm{GN} \mathrm{m}^{-1}$ to $800 \mathrm{GN}$ $\mathrm{m}^{-1}$ by $18.5 \mathrm{Myr}$ (Fig. 3d). This model illustrates the standard case in which subducting oceanic lithosphere remains coupled to the retro-continent, consistent with the similar tectonic forces acting on the pro- and retro-lithospheres at the boundaries (Fig. 3d). No decoupling develops, and consequently there is no forearc spreading.

\subsection{Model FA-R: Forearc retreat and 'proto-ophiolite' generation}

Model FA-R $\left(\Delta \rho_{\text {OLM }}=20 ; f_{\text {sed }}=0.3\right.$; Fig. 4$)$ has less depletion and weaker coupling than Model FA-C, and lies near the mid-range of parameter values in our experimental template (Fig. 2). Like Model FA-C, subduction initially has a shallow trajectory, and the corresponding tectonic force is again compressive $\left(\sim-2800 \mathrm{GN} \mathrm{m}^{-1}\right)$. Later, the slab steepens as slab length and slab pull increase (Fig. 4a). Subduction continues normally until $\sim 8 \mathrm{Myr}$, when the slab has reached the base of the upper mantle and the tectonic force is $\sim 3800 \mathrm{GN} \mathrm{m}^{-1}$ (Fig. 4e), at which point the subduction zone decouples (Fig. 4b). Immediately the trench and subduction zone retreat, exhuming deeply buried sediment (Fig. 4f) and sub-lithospheric mantle along the subduction zone into the incipient forearc ocean basin (Fig. 4b, c; 8.5 and 12 Myr). As the sub-lithospheric mantle exhumes it forms new proto-ophiolite forearc crust and mantle. Trench retreat continues and the slab pivots to a shallower angle (Fig. 4c). The net tectonic force acting on the oceanic lithosphere increases to $>4000 \mathrm{GN} \mathrm{m}^{-1}$ at the boundary, owing to the increase in the subducted length of slab, as well as the loss of inter-plate coupling. Initially, the trench retreats very rapidly, producing an approximately 450-km-wide forearc ocean basin with a symmetric spreading centre in about $4 \mathrm{Myr}$, i.e., a full spreading rate of $\sim 11 \mathrm{~cm} \mathrm{a}^{-1}$ (Fig. 4c; $12 \mathrm{Myr}$ ). Subduction zone retreat slows dramatically at $\sim 14.5 \mathrm{Myr}$ but forearc ocean basin spreading continues, in part driven by entrainment and removal of forearc basin lithosphere by the subducting slab (Fig. 4c, d, ablative subduction, orange). The pivoted slab sags until the upper subducting part becomes steeper, and subsequent subduction is accommodated by sliding its subhorizontal lower part along the base of the upper mantle. By 18.5 Myr, the upper slab has nearly regained its original trajectory, and the forearc ocean has a total width of 
$\sim 600 \mathrm{~km}$ (Fig. 4d). This model illustrates how combined moderate slab pull and inter-plate coupling leads to decoupling of the subduction zone and consequent forearc spreading, producing a forearc oceanic rift basin containing proto-ophiolite lithosphere.

3.4 Model FA-B-R: Slab breakoff followed by subduction re-initiation and subduction zone retreat

Model FA-B-R $\left(\Delta \rho_{O L M}=20 ; f_{\text {sed }}=0.5\right.$; Fig. 5$)$ is the same as Model FA-R, except with increased oceanic sediment viscosity, medium versus moderate, resulting in enhanced inter-plate coupling. The initial evolution is like Models FA-C/FA-R, with early coupled subduction. The slab tensile force grows as it transits the upper mantle, reaching a maximum of $\sim 3800 \mathrm{GN} \mathrm{m}^{-1}$ (Fig. 5 f). At $\sim 9.5 \mathrm{Myr}$ the subduction zone decouples, with minor slab retreat. However, rather than continuing to retreat, the slab fails, then breaks off at a shallow level (Fig. 5b). The pro-lithosphere tectonic force plummets in response to the loss of slab pull, and becomes compressive ( $\sim 2000 \mathrm{GN} \mathrm{m}^{-1}$, Fig. $\left.5 f\right)$. Subduction then resumes at a shallow angle and becomes progressively steeper (Fig. 5c, d). At $\sim 21 \mathrm{Myr}$ the re-initiated subduction zone decouples (Fig. $5 \mathrm{~d}$, f) when the net tectonic force is $\sim 3700 \mathrm{GN}$ $\mathrm{m}^{-1}$. This time the slab retreats, forming a forearc spreading centre, oceanic rift basin and proto-ophiolite (Fig. 5e). Overall, the model is like Model FA-R, but with forearc opening delayed owing to the earlier slab-breakoff. Like Model FA-R, the model undergoes an initial phase of rapid subduction zone retreat forming a $\sim 400$-km-wide forearc in $\sim 3 \mathrm{Myr}$, i.e., a full spreading rate of $\sim 13 \mathrm{~cm} \mathrm{a}^{-1}$. Some spreading is again assisted by entrainment of the forearc lithosphere by the subducting slab, particularly as subduction zone retreat slows. By 27.5 Myr, the forearc basin proto-ophiolite is $550 \mathrm{~km}$ wide (Fig. 5e). The slab has regained a moderate trajectory, with a region lying nearly flat on the upper/lower mantle boundary. This model illustrates the case in which forearc spreading takes place after protracted convergence, including a slab break-off and subsequent re-initiation of subduction.

\subsection{Sensitivity of models to slab pull and coupling strength}

Figure 2 summarizes the template experiments testing the effects of $\Delta \rho_{O L M}$ and $f_{\text {sed. }}$. The main behavior ( $C, R, B$ ) for each is identified, and corresponding timing and force of subduction zone decoupling is listed. Models with minor depletion $\left(\Delta \rho_{O L M} \sim 10-20 \mathrm{~kg} \mathrm{~m}^{-3}\right)$ and weak/moderate coupling $\left(f_{\text {sed }}=0.1,0.3\right)$ have a strong tendency toward decoupling and 
subduction zone retreat (e.g. Model FA-R) when the tectonic slab pull force at the proboundary is $2700-3700 \mathrm{GN} \mathrm{m}^{-1}$. Only models with high depletion $\left(\Delta \rho_{O L M}=30 \mathrm{~kg} \mathrm{~m}^{-3}\right)$ and/or medium/strong coupling $\left(f_{\text {sed }}=0.5,1\right)$ do not decouple. In these cases, the subducted lithosphere enters the lower mantle followed by decreasing tectonic slab pull. The latter suggests that there is an optimal window for slab decoupling corresponding to the time shortly before the slab enters the more viscous lower mantle.

For models that decouple, variations in $\Delta \rho_{O L M}$ and $f_{\text {sed }}$ cause systematic differences in the timing of slab decoupling (Fig. 2). A model with $\Delta \rho_{O L M}=10 \mathrm{~kg} \mathrm{~m}^{-3}$ and $f_{\text {sed }}=0.1$ decouples at 5.2 Myr, compared to 7.9 Myr for Model FA-R, whereas a model with $\Delta \rho_{O L M}=$ $30 \mathrm{~kg} \mathrm{~m}^{-3}$ and $f_{\text {sed }}=0.3$ decouples at 10.4 Myr. While the differences in the timing of subduction zone retreat are systematic, they are subtle. Significantly, even the most likely to decouple model $\left(\Delta \rho_{O L M}=10 \mathrm{~kg} \mathrm{~m}^{-3}\right.$ and $\left.f_{\text {sed }}=0.1\right)$ requires a considerable length of subducted slab and corresponding tensile slab pull force to decouple the subduction zone.

Models that produce slab break-off tend to have a low/moderate depletion combined with a medium/strong $f_{\text {sed }}=0.5-1$. In addition, not all models that produce slab break-off undergo later decoupling and subduction zone retreat. The model with $\Delta \rho_{O L M}=$ $20 \mathrm{~kg} \mathrm{~m}^{-3}$ and $f_{\text {sed }}=1$, for example, produces break-off and re-initiation of subduction, but remains coupled. Model $\Delta \rho=10 \mathrm{~kg} \mathrm{~m}^{-3} ; f_{\text {sed }}=1$ produces a slab break-off and subduction reinitiation followed by rifting of the back-arc region, rather than the forearc (Fig. $5 \mathrm{~d}$ inset). Back-arc rifting is attributed to the combination of high slab pull ( $\left.\sim 200 \mathrm{GN} \mathrm{m}^{-1}\right)$ and strong coupling, making the coupled forearc stronger than the retro-lithosphere. In summary, slab pull and interplate coupling exert strong controls on the style of subduction, with only minor changes in either required to translate the model behavior from a coupled (Model FA-C) to decoupled regime with forearc spreading (Model FA-R). Following slab break-off, models may evolve to coupled or decoupled subduction regimes, depending on the combination of slab pull and coupling.

\section{Analysis of forearc decoupling}

We now investigate the mechanism of subduction zone decoupling using Model FA- $R$ as an example $\left(\Delta \rho_{\mathrm{OLM}}=20 \mathrm{~kg} \mathrm{~m}^{-3}, f_{\text {sed }}=0.3\right)$. Subduction zone retreat in models with a fixed retro- 
lithosphere (as though attached to a large continental plate, e.g., Eurasia) requires precursor decoupling. In nature, and in models, extension commonly develops in the back arc region (e.g., Capitanio et al., 2010), although there are also several model examples that demonstrate forearc and intra-arc extension (e.g., Gorczyk et al., 2007; Gerya and Meilick, 2011; Vogt et al., 2012; Baitsch-Ghirardello et al., 2014). Back-arc rifting is generally attributed to strong coupling between the subducting and overlying lithospheres owing to basal traction from the entrained viscous flow in the mantle wedge driven by the subducting lithosphere (Sleep and Toksoz, 1971). Beyond the mantle wedge in the back-arc region this traction abates making this region susceptible to rifting.

In our models subducting lithosphere is steep, giving a narrow mantle wedge region of viscous coupling, plus the viscous flow causing this coupling is weak (Figs 3b,c; 4a; 5a). The narrow coupled region means the forearc region is now vulnerable to decoupling and rifting. In all models that decouple except one (Fig. 2, models labelled R), decoupling is in the forearc by failure of the frictional-plastic crust combined with opening of the viscous subduction channel. The exception is model BA-B-R (Backarc-Breakoff-Retreat, (Figs 2 and 5d) which rifts the backarc, followed by subduction zone retreat. In this case the forearc region is actually stronger than the retro-lithosphere owing to the strong viscous coupling, $f_{\text {sed }}=1$. Forearc decoupling can be explained using simple analytical models.

\subsection{Failure of the frictional-plastic crust}

Frictional-plastic crust with the Drucker-Prager failure criterion (Appendix A1) is on tensile yield, $\sigma_{Y}$ (tension considered positive), when:

$\sigma_{Y}=\sigma_{z z} \operatorname{Sin} \phi /(1+\operatorname{Sin} \phi)$

where $\sigma_{z z}$ is the vertical stress, approximated as the lithostatic pressure, $\rho g z$, and $\phi$ is the effective internal angle of friction taking into account pore fluid pressure (Appendix A1). Integrating through the layer thickness, $L_{P}$, gives the force, $F_{P}$, necessary to put the layer on tensile yield:

$$
F_{P}=\left(\rho g L_{P}^{2} \operatorname{Sin} \phi\right) / 2(1+\operatorname{Sin} \phi) \text {. }
$$

From the model results, the maximum thickness $L_{P}$ of the forearc frictional-plastic crustal layer just before decoupling is $\sim 35 \mathrm{~km}$, with underlying viscous subduction channel below yield (Fig. 6a). For this $L_{P}$ and crustal density $2800 \mathrm{~kg} \mathrm{~m}^{-3}, F_{P}$ ranges from $\sim 3500 \mathrm{GN}$ $\mathrm{m}^{-1}\left(\phi=15^{\circ}\right)$ to $\sim 2500 \mathrm{GN} \mathrm{m}^{-1}\left(\phi=10^{\circ}\right)$ to $\sim 1400 \mathrm{GN} \mathrm{m}^{-1}\left(\phi=5^{\circ}\right)$. 
351 Viscous decoupling of the lower lithosphere can be approximated by the Stefan adhesion 352 problem, that of separating rigid parallel plates containing a viscous fluid (Stefan, 1874).

353 The problem concerns the perpendicular separation of one plate from the other at rate $d H_{V} / d t$, where $H_{V}$ is the spacing between the plates, in our case the width of the viscous subduction channel (Fig. 6). Separation requires flux balance between viscous fluid flow into space created by plate separation, and the longitudinal channel viscous Poiseuille flux, $U$, induced by plate separation. Reynold's (lubrication) equation for flow in the dip direction $x$ becomes:

$d H_{V} / d t=-d U / d x=-\left(H_{V}^{3} / 12 \eta\right) d / d x(d P / d x)$ where $H_{V}$ and fluid viscosity, $\eta$, are assumed constant and $P$ is pressure. Rearranging in terms of $d P / d x$ and integrating twice gives: $P(x)=6 \eta\left(\frac{x^{2}-L_{V}^{2}}{H_{V}^{3}}\right)\left(\frac{d H_{V}}{d t}\right)+P_{\text {ext }}$ where $L_{V}$ is the dip length of the viscous part of the channel and $P_{\text {ext }}$ is the excess external buoyancy pressure at the base of the channel. Integrating $P(x)$ down the channel gives the viscous force per unit strike length required to separate the plates when $P_{\text {ext }}=0$ :

$F_{V}=4\left(\eta / H_{V}^{3}\right) L_{V}^{3} d H_{V} / d t$

$367 P_{\text {ext }} \sim 0$ in the models because we set UHP sediment density to mantle values.

368 Correspondingly, the rate of separation for force $F_{V}$ is:

$369 d H_{V} / d t=F_{V} H_{V}^{3} / 4 \eta L_{V}^{3}$

As an example, taking values similar to those in the models; $F_{V}=4000 \mathrm{GN} \mathrm{m}^{-1}$ (Fig. 6f),

$37210^{5}$ years. Once $H_{V}$ increases to $20 \mathrm{~km}$ the velocity will be $2^{3}$ larger, nearly an order of 373 magnitude faster.

$374 \quad 4.3$ Combined frictional-plastic failure and viscous separation

375 Using this simple analysis, subducting lithosphere must apply a tensile tectonic force, $376 F_{T}=F_{P}+F_{V}$, to the retro-lithosphere that puts the frictional-plastic crust on yield and 377 simultaneously separates the underlying viscous channel. This requires $F_{T} \sim 7500 \mathrm{GN} \mathrm{m}^{-1}$ 378 for our type of model. However, models actually decouple with net slab pull tectonic forces 379 (monitored in the lithosphere at the model boundaries) of $\sim 4000 \mathrm{GN} \mathrm{m}^{-1}$ (e.g. Fig. $6 f$ ). 
Decoupling (Fig. 6) is achieved by a modified form of the analysis described above, in which the frictional-plastic crust is first put on yield (Step 1, 7.3 Myr, Fig. 6a, f), followed by the separation in the viscous channel starting at the base, where the channel is the widest and has the lowest viscosity (Step 2, 7.4 Myr, Fig. 6b, e). Separation then migrates progressively up the channel, a process akin to opening a hinge (Fig. 6c, d,), with late-stage extension of the plastic crust (Fig. 6d, f, Steps 3, 4) completing decoupling. 'Hinge-style' decoupling stems from slower separation in the upper viscous channel, where the viscosity is higher and channel width smaller (Fig. 6b) (Equation 3). The hinge-style is more efficient because it allows force to be transferred to the narrower (smaller $H_{V}$ ), and viscously stronger upper channel once the lower channel widens sufficiently that less force can maintain its rate of separation. Hinging effectively decreases $L_{V}$ as separation progresses. Decoupling in Model FA-R spans 7.3-8.5 Myr, corresponding to the approach of the subducting slab to the base of the upper mantle at $5 \mathrm{~cm} \mathrm{yr}^{-1}$. Both boundary forces increase approximately linearly, reflecting the rapid increase in net slab pull (Fig. 6f). They diverge once the plates cease to be well coupled.

The template of models (Fig. 2) allows us to investigate how this system is controlled by the $f_{\text {sed }}$-value in the quartzite power-law flow for the sediments in the subduction channel, which directly scales the viscosity, $\eta$, and the net slab pull force (e.g. Figs 3-6) determined by the depletion density. In addition, models with the same $f_{\text {sed }}$ and depletion density were computed for a range of retro-lithosphere $\phi$ values. Decreasing $\phi$ $\left(15^{\circ}, 10^{\circ}, 5^{\circ}\right)$ allows decoupling at lower values of the net slab pull (respectively 3800 , 3600, $3200 \mathrm{GN} \mathrm{m}^{-1}$ ), with corresponding decoupling at 7.8, 7.5 and $7 \mathrm{Myr}$. These $\phi$ variations have relatively small effects on the models, but the effective slab pull forces are in general agreement with the estimates of $F_{P}$ (section 4.1) for the same range of $\phi$. By comparison, viscosity scaling of the quartzite flow law $\left(f_{\text {sed }}=0.1-1.0\right)$ causes larger delays, 1-3 Myr, in times of decoupling, larger values of the boundary forces for $f_{\text {sed }}=0.3-1.0$ than with $f_{\text {sed }}=0.1$, and no forearc decoupling for $f_{\text {sed }}=1$. These are not surprising because decoupling rate scales inversely with viscosity (Equation 3), thereby delaying and slowing decoupling while the boundary net slab pull force increases substantially during the delay (Figs. 2, 6). The two main controls on decoupling are therefore the depletion density 
$410\left(\Delta \rho_{\text {OLM }}\right)$, which determines the slab pull, and $f_{\text {sed, }}$, which explains why we focused on them 411 in Figure 2 and Section 3.

\section{5 . Implications for formation of the Xigaze ophiolite}

413 Our model results can explain formation of the Xigaze group ophiolites, southern Tibet, 414 some of the many ophiolites arrayed along the $\sim 2,000 \mathrm{~km}$ Yarlung Zangbo Suture Zone 415 (YZSZ) within the Himalayan-Tibetan orogen (Hébert et al., 2012). Exposed for $250 \mathrm{~km}$ along strike, the Xigaze ophiolite consists of serpentinized mantle peridotite, capped by a thin crustal sequence comprising minor cumulates, gabbros, sheeted dykes, pillow basalts, and cherts interpreted as obducted remnants of Neo-Tethyan oceanic lithosphere (Nicolas, 1981; Huang et al., 2015). South of, and tectonostratigraphically beneath, the Xigaze ophiolite lies a serpentinite melange with exotic amphibolites interpreted as remnants of a metamorphic sole (Guilmette et al., 2008, 2009). The marine clastic Xigaze Group to the north comprises forearc detritus derived from the Gangdese Batholith at the southern margin of the Lhasa terrane (Dürr, 1996; Orme et al., 2015). U-Pb and hornblende ${ }^{40} \mathrm{Ar} /{ }^{39} \mathrm{Ar}$ ages of the Xigaze ophiolite indicate formation between 133-121 Ma (Fig. 7a) (Guilmette et al., 2009; Dai et al., 2013; Chan et al., 2015), consistent with late Barremian to late Albian radiolaria within the overlying cherts (Aitchison et al., 2003; Ziabrev et al., 2003).

The tectonic setting where Xigaze ophiolite formed remains controversial (e.g., Hébert et al., 2012), but increasing evidence indicates it formed in the Lhasa terrane forearc. The base of the Xigaze Group is locally in depositional contact with the ophiolite (An et al., 2014; Huang et al., 2015), and both are of similar age (maximum depositional ages of 129-114 Ma; Huang et al., 2015). Paleomagnetic data indicate that these basal sandstones were deposited at paleolatitude $16.2[+4.7 /-3.2]^{\circ} \mathrm{N}$ (Huang et al., 2015), indistinguishable from the Early Cretaceous paleolatitude of the Lhasa terrane $\left(14.7 \pm 5.5^{\circ} \mathrm{N}-18.6 \pm 2.1^{\circ} \mathrm{N}\right.$ ) (Chen et al., 2012; Ma et al., 2014; Huang et al., 2015; Yang et al., 2015). Geochemical characteristics of the Xigaze ophiolite, in particular negative $\mathrm{Nb}-\mathrm{Ta}$ anomalies and U-shaped REE patterns (in mantle peridotites), point to modification of the mantle source by slab-derived fluids, consistent with a SSZ origin (Xia et al., 2003; Malpas et al., 2003; Dubois-Côte' et al., 2005; Hébert et al., 2012). 
The presence of early MORBs followed by late-stage boninites (Dai et al., 2013), and

441

442

443

444

445 ultra-depleted harzburgitic mantle peridotites (Dubois-Côté et al., 2005) in particular, have prompted comparisons with the Izu-Bonin-Mariana (IBM) system and other forearc ophiolites (Reagan et al., 2010; Dai et al., 2013). By analogy with the IBM system, several authors have suggested that Xigaze ophiolite formed by forearc seafloor spreading in response to subduction initiation, as in the conceptual models of Stern (2004), and Whattam and Stern (2011). Dai et al. (2013) proposed that subduction of Neo-Tethyan oceanic lithosphere initiated shortly before $130 \mathrm{Ma}$ forearc spreading (Fig. 7d) as a consequence of the collision between the Lhasa terrane and the Qiangtang terrane to the north. Rollback of the subducting slab led to decompression melting, forming forearc basalts with MORB affinities (Fig. 7e). Fluids released from the subducting lithosphere enhanced melting and depletion of the mantle wedge, creating depleted harzburgite and associated boninite melts. Finally, the stabilized subduction zone magmatic front migrated northward to beneath the Lhasa terrane, reactivating the Gangdese Arc (Fig. 7a, f).

The problem with applying the subduction initiation model to the Xigaze ophiolite is that the adjacent Gangdese Arc (GA) may already have been active, suggesting earlier subduction. Late Triassic ( $220 \mathrm{Ma}$ ) subduction is controversial (Chu et al., 2006; Ji et al., 2009; Wu et al., 2010; Zhu et al., 2011; Wang et al., 2016), but most authors agree that northward subduction of Neo-Tethyan oceanic lithosphere was underway by Late Jurassic ( $160-150 \mathrm{Ma})$ - the age of magmatism within the Zedong Terrane in central Tibet (McDermid et al., 2002; Zhang et al., 2013). However, this appears at odds with recent evidence (Li et al., 2016) that the Lhasa terrane drifted northward by $4500 \mathrm{~km}$ during the Jurassic, such that it was in a plate tectonic setting that would not favor northward directed subduction beneath its southern boundary. The two interpretations may be reconciled if the full rate of seafloor spreading in the Neo-Tethys south of the Lhasa terrane during the Jurassic was greater than the northward rate of its motion, $5 \mathrm{~cm} \mathrm{a}^{-1}$ (Li et al., 2016), which would then permit, but not require, subduction beneath the southern Lhasa terrane during the latter part of its northward journey. If the 160-150 Ma magmatism is related to northward subduction beneath the Lhasa terrane, the Xigaze ophiolite appears to have formed late, in a hiatus in arc magmatism from 150-120 Ma (Fig. 7a; e.g., Dai et al., 2013). Based on our modeling, we suggest an alternative explanation for the formation of the 
471 Xigaze forearc ophiolite which incorporates the need for a precursor phase of oceanic

472 subduction. This evolution (Fig. 7b-f) is based on conceptual models (Dai et al., 2013),

473 supplemented by our interpretation pre-130 Ma (Fig. 7b-d). Corresponding frames from

474 Model FA-B-R are shown in Figure 7g-j.

In this modified interpretation, northward subduction of Neo-Tethyan oceanic lithosphere beneath the Lhasa terrane was underway at $160 \mathrm{Ma}$ (Fig. 7b, g), producing a phase of GA magmatism from 160-150 Ma. Subduction may have continued until the onset of subduction zone retreat (Fig. 7b-d and g-i arrows). However, this is not compatible with an inferred gap in GA magmatism from 150 to $120 \mathrm{Ma}$ (Fig. 7a). Termination of GA magmatism 150 Ma may have resulted from: 1) transfer of subduction to the north during closure of the Lhasa and Qiangtang terranes; 2) break-off of the subducting Neo-Tethyan oceanic lithosphere beneath the GA, or; 3) onset of subduction zone retreat. Explanation 3 is difficult to reconcile with measured ages of the Xigaze ophiolite crust, indicating rapid formation from 130-120 Ma, 20 Myr later than the onset of the GA magmatic gap. We favour Explanation 2 (possibly linked to Explanation 1), such that slab break-off was followed by subduction re-initiation sufficiently before 130 Ma that the renewed slab pull caused subduction zone decoupling at $130 \mathrm{Ma}$ (Fig. 7b, c, d and g, h, i, paths) as observed in Model FA-B-R (Fig. 5) and consistent with Zhu et al. (2009). The only requirement is that forearc inter-plate coupling was overcome by the slab pull force (Fig. 7i). Rapid subduction zone retreat (Fig.7e) then formed the 'Xigaze forearc ocean basin', as in the model (Fig. 7j), requiring only a few million years. sequence of MORB-IAT-boninitic magmatism and mantle depletion characteristic of SSZ forearc ophiolites cannot be demonstrated from our models. However, it is consistent in that the rapid model subduction zone retreat causes such a dramatic influx of sublithospheric mantle (e.g. Fig 7i, j) that any slab fluid-derived component would be overwhelmed until retreat slowed and the forearc stabilized, thus producing the expected magmatic sequence. The resumption of GA magmatism at $\sim 120 \mathrm{Ma}$ is consistent with northward advance of the Neo-Tethyan slab (Fig. 7f). Our models do not completely explain 500 this subduction zone advance, but a subset of models does exhibit late-stage subduction 501 zone advance by up to $200 \mathrm{~km}$. Our 2D models also cannot address possible extension in 
the third dimension. Such arc-parallel extension (e.g., van Hinsbergen and Schmid, 2012) could explain formation of proto-ophiolite lithosphere while requiring less trench-normal retreat than that seen in the models.

\section{An explanation for ultrahigh-pressure/transition zone phases in Yarlung Zangbo} Suture Zone (YZSZ) ophiolites

Our model results can also be used to explain the enigmatic ultrahigh-pressure (UHP; P>2.5 GPa) and inferred transition zone (TZ; P>10 GPa) phases found in some YZSZ ophiolites (e.g., Yang et al., 2014; Griffin et al., 2016). Evidence of an extremely deep origin, coesite (including pseuodmorphs of stishovite), diamond, and other UHP/inferred TZ phases, is found in peridotites and podiform chromitites from several YZSZ ophiolite massifs, notably the Luobusa ophiolite east of the Xigaze ophiolite (Robinson et al., 2004; Yang et al., 2007; Yamamoto et al., 2009). Detailed petrological studies show Luobusa chromites have trace element signatures consistent with a shallow origin, but contain super-reducing UHP mineral inclusions indicative of formation in the mantle transition zone ( $>400 \mathrm{~km}$ ) (McGowan et al., 2015). These features are interpreted as evidence of shallow formation of peridotites, then subduction of peridotite containing chromitites into the transition zone at or before $\sim 375 \mathrm{Ma}$, and later rapid exhumation and incorporation into the Luobusa proto-ophiolite (McGowan et al., 2015; Griffin et al., 2016) at 170-150 $\mathrm{Ma}$, the age of formation of the Luobusa ophiolite crust.

We interpret the models to indicate that deep mantle exhumation, as inferred for the UHP Luobusa peridotites/chromitites, may be intimately linked to subduction zone decoupling and retreat. In Model FA-R, for example, subduction is accompanied by a counter-clockwise mantle-scale flow which accelerates greatly during rapid subduction zone retreat (Fig. 4a, b), possibly leading to deep mantle exhumation. To examine this exhumation, Model FA-R was re-computed with marker blocks placed in the mantle transition zone ( $\geq 400 \mathrm{~km}$ ) at the time of subduction zone decoupling. In FA-R-EX1 (Figs $8 \mathrm{a}-\mathrm{c}$ and $\mathrm{S} 1$ ) blocks have the same properties as the surrounding mantle and are neutrally buoyant. In Model FA-R-EX2 (Figs 8d-f and S2) blocks are variably depleted by 0 to $50 \mathrm{~kg}$ $\mathrm{m}^{-3}$ (color scale Fig. 8e). Model FA-R-EX1 shows vigorous circulation and exhumation of transition zone mantle linked to flow into the forearc region. However, there are two 
largely decoupled flow regimes (Fig. 8). The lower one exhumes the neutrally buoyant blocks, but blocks remaining below $\sim 250 \mathrm{~km}$ are entrained in the slab boundary layer flow and re-subducted. Only material in the upper flow, $<250 \mathrm{~km}$, flows laterally and upward into the void created by subduction zone retreat. This style of circulation explains UHP material with pressures up to $\sim 8 \mathrm{GPa}$ in the proto-ophiolite (Fig. $8 \mathrm{c}$ ), but not TZ material. In Model FA-R-EX2, however, the minor buoyancy-driven increase in their vertical velocity carries blocks from the lower circulation into the upper one, incorporating TZ-derived blocks into the proto-ophiolite in only $6 \mathrm{Myr}$ from the onset of subduction zone retreat (Fig. 8d-f). Blocks with depletion as low as $20 \mathrm{~kg} \mathrm{~m}^{-3}$ are in the same region by $9.5 \mathrm{Myr}$ (Fig. S2). Maximum pressures recorded by exhumed blocks reach $\sim 14$ GPa at both 6 Myr (Fig. 8f) and 9.5 Myr (Fig. S2).

These findings are consistent with the hypothesis that the Luobusa mantle blocks may have originated as sub-continental or forearc oceanic lithosphere, and were depleted prior to their deep subduction and subsequent exhumation (Griffin et al., 2016). We suggest that Luobusa UHP peridotites/chromitites can be exhumed as in FA-R-EX2, by rapid large-scale mantle upwelling associated with subduction zone retreat, accompanied by minor buoyancy assist from depletion. The initial temperatures of the exhumed material are $1300-1550^{\circ} \mathrm{C}$, and the pressure-temperature path corresponds to nearadiabatic decompression. Alternatively, standard/non-TZ UHP phases (e.g., diamonds) are easily incorporated into proto-ophiolites (e.g., Xigaze ophiolites) by upper level flow without need for depletion. It is also possible that the TZ UHP phases were incorporated into the Lhasa sublithospheric mantle at an earlier stage and exhumed into the ophiolite during forearc extension. However, this explanation begs the question of the mechanism for their original exhumation from the transition zone.

The model results also show a mechanism for the original burial of the UHP/TZ material. If Models FA-R-EX1/EX2 are instead interpreted to represent the original SSZ setting in which the chromites and peridotites formed, it can be seen that a significant volume of the forearc mantle lithosphere, particularly depleted mantle lithosphere ( $\Delta \rho_{\text {OLM }}$ $=30 \mathrm{~kg} \mathrm{~m}^{-3}$ ) is entrained by the upper surface of the subducting slab and subducted to TZ depths (Figs 8, S1 and S2). In fact, Model FA-R-EX2 also shows recently exhumed UHP/TZ material encased in this downward flow, material destined for its second bout of TZ 
571

metamorphism. Although geodynamical models of subducted slab rollback have been used to support exhumation from the TZ (McGowan et al., 2015; Griffin et al., 2016) we suggest that the vigorous flow associated with rapid subduction zone retreat provides a more convincing explanation, plus the appropriate setting for incorporation into SSZ protoophiolites. That TZ UHP phases appear to be rare in SSZ ophiolites may result from the need for both a vigorous circulation and depleted, buoyant material appropriately located in the transition zone.

\section{Alternative models for Supra-Subduction Zone (SSZ) proto-ophiolites}

A popular model for SSZ forearc proto-ophiolites is that they are created following the initiation of spontaneous or induced subduction (Stern and Bloomer, 1992; Stern, 2004). The underlying idea is that asthenosphere will initially 'flood' the cold foundering lithosphere, making it negatively buoyant as subduction begins. Rollback/subduction zone retreat follows, leading to formation of the forearc extensional ocean basin and protoophiolite. This may be a viable mechanism for subduction zones initiated at oceanic transform faults (Stern, 2004) or other settings where the subducting plate is old/cold and negatively buoyant, and the upper plate is hot and thin, although it should be noted that this mechanism fails to explain metamorphic sole formation and exhumation (van Hinsbergen et al., 2015).

Our models investigate the contrasting case of subduction and decoupling of $\sim 100$ Myr-old oceanic lithosphere at an active continental margin. Even when the coupling is extremely low $\left(f_{\text {sed }}<<1\right)$ there is no tendency for flooding the subducting lithosphere, nor subduction zone retreat, until hundreds of kilometers of subduction give enough slab pull for bending and decoupling. Our model results do not support the subduction initiation conceptual model for active continental margins. We suggest that the 'decoupling-retreat' and 'subduction-initiation' explanations are alternatives operating in different tectonic settings. In particular, the decoupling-retreat model is consistent with the Xigaze group ophiolites, in that they are interpreted to have formed at an active continental margin (Xiong et al., 2016) with indirect evidence of an earlier phase of subduction with the same polarity (Fig. 7) (Wang et al., 2016). An alternative is that decoupling-retreat was preceded by slab breakoff and the re-initiation of subduction (Figs. 5 and 7). Distinguishing between 
decoupling-retreat and subduction-initiation mechanisms in the geological record can be based on evidence of prior subduction, such as arc magmatism, before decoupling, whereas this would be absent in the case of subduction initiation.

Our results imply that mature subduction zones need only experience a minor reduction in coupling in order to decouple (Fig. 2), possibly owing to a decrease in the viscosity or increase in volume of weak material in the subduction channel. Such variations in sediment strength and volume may arise naturally owing to changes in sediment sources or fluxes into the subduction zone. In addition, other processes not considered here (e.g., fluid or melt weakening) may weaken the retro-lithosphere, whereas the forearc mantle may be weakened by serpentinization (Gorczyk et al., 2007; Gerya and Meilick, 2011; Vogt et al., 2012; Baitsch-Ghirardello et al., 2014).

\section{Conclusions}

We have presented results from numerical model experiments designed to investigate the controls on subduction zone decoupling and forearc proto-ophiolite generation at active continental margins. Our key findings are as follows.

1. Models exhibit three styles of subduction controlled by the slab pull force and interplate coupling: coupled subduction, forearc decoupling and subduction zone (trench) retreat, leading to: forearc proto-ophiolite generation; slab break-off and re-initiation of subduction; and in some cases delayed subduction zone retreat.

2. Subduction zone decoupling can be interpreted analytically by frictional-plastic yield theory and the Stefan solution for the separation of plates containing a viscous fluid.

3. The models are used to explain the formation of Xigaze group ophiolites, southern Tibet, which formed in the Lhasa terrane forearc possibly following earlier subduction. Either there was coupled subduction before subduction zone decoupling, or precursor slab breakoff, subduction re-initiation, and then decoupling.

4. Rapid deep upper-mantle circulation in the models during subduction zone retreat can exhume and emplace material from as deep as the mantle transition zone in the forearc proto-ophiolite, thereby explaining diamonds and 10-15 GPa UHP phases in Tibetan ophiolites.

\section{Acknowledgements}


626 This project was generously supported by the National Science Foundation Continental 627 Dynamics project EAR-1008527; Paul Kapp et al., 'Collaborative Research: The Suturing 628 Process: Insight from the India-Asia Collision Zone' through a sub-contract, and by an 629 NSERC Discovery Grant to CB. CB also acknowledges support from the Canada Research 630 Chair in Geodynamics. Numerical models used the software SOPALE-nested developed 631 from SOPALE by D. Guptill, B. Lee and members of the Dalhousie Geodynamics Group. 632 SOPALE was originally developed at Dalhousie University by P. Fullsack. We thank Paul 633 Kapp and members of the 'Suture' team, and Becky Jamieson for discussions critical to the 634 success of this research. We also thank Becky Jamieson and reviewers Taras Gerya and 635 Douwe van Hinsbergen for their thoughtful comments on the manuscript. 


\section{References}

Aitchison, J.C., Davis, A.M., Abrajevitch, A.V., Ali, J.R., Liu, J., Luo, H., McDermid, I.R. and Ziabrev, S.V., 2003. Stratigraphic and sedimentological constraints on the age and tectonic evolution of the Neotethyan ophiolites along the Yarlung Tsangpo suture zone, Tibet. Geological Society, London, Special Publications, 218, 147-164, doi:10.1144/gsl.sp.2003.218.01.09.

An, W., Hu, X., Garzanti, E., BouDagher-Fadel, M.K., Wang, J. and Sun, G., 2014. Xigaze forearc basin revisited (South Tibet): Provenance changes and origin of the Xigaze Ophiolite. Geological Society of America Bulletin, 126, 1595-1613, doi:10.1130/b31020.1.

Anonymous, 1972. Penrose Field Conference on ophiolites. Geotimes, 17, 24-25.

Baes, M., Govers, R. and Wortel, R., 2011. Subduction initiation along the inherited weakness zone at the edge of a slab: Insights from numerical models. Geophysical Journal International, 184, 991-1008, doi:10.1111/j.1365-246x.2010.04896.x.

Baitsch-Ghirardello, B., Gerya, T.V., Burg, J.-P., 2014. Geodynamic regimes of intra-oceanic subduction: Implications forearc extension vs. shortening processes. Gondwana Research, $25,546-560$.

Beaumont, C., Jamieson, R.A., Nguyen, M.H. and Lee, B., 2001. Himalayan tectonics explained by extrusion of a low-viscosity crustal channel coupled to focused surface denudation. Nature, 414, 738-742.

Beaumont, C., Jamieson, R.A., Butler, J.P. and Warren, C.J., 2009. Crustal structure: A key constraint on the mechanism of ultra-high-pressure rock exhumation. Earth and Planetary Science Letters, 287, 116-129, doi:10.1016/j.epsl.2009.08.001.

Beaumont, C., Nguyen, M.H., Jamieson, R.A. and Ellis, S., 2006. Crustal flow modes in large hot orogens. Geological Society, London, Special Publications, 268(1), 91-145.

Billen, M.I., 2010. Slab dynamics in the transition zone. Physics of the Earth and planetary interiors, 183, 296-308, doi:10.1016/j.pepi.2010.05.005.

Butler, J.P., Beaumont, C. and Jamieson, R.A., 2013. The Alps 1: A working geodynamic model for burial and exhumation of (ultra) high-pressure rocks in Alpine-type orogens. Earth and Planetary Science Letters, 377, 114-131.

Butler, J.P., Beaumont, C. and Jamieson, R.A., 2014. The Alps 2: Controls on crustal subduction and (ultra) high-pressure rock exhumation in Alpine-type orogens. Journal of Geophysical Research: Solid Earth, 119, 5987-6022. 
Capitanio, F.A., Stegman, D.R., Moresi, L.N. and Sharples, W., 2010. Upper plate controls on deep subduction, trench migrations and deformations at convergent margins. Tectonophysics, 483, 80-92, doi:10.1016/j.tecto.2009.08.020.

Chan, G.H.N., Aitchison, J.C., Crowley, Q.G., Horstwood, M.S., Searle, M.P., Parrish, R.R. and Chan, J.S.L., 2015. U-Pb zircon ages for Yarlung Tsangpo suture zone ophiolites, southwestern Tibet and their tectonic implications. Gondwana Research, 27, 719-732, doi:10.1016/j.gr.2013.06.016.

Chen, W., Yang, T., Zhang, S., Yang, Z., Li, H., Wu, H., Zhang, J., Ma, Y. and Cai, F., 2012. Paleomagnetic results from the Early Cretaceous Zenong Group volcanic rocks, Cuoqin, Tibet, and their paleogeographic implications. Gondwana Research, 22, 461-469, doi:10.1016/j.gr.2011.07.019.

Chu, M.F., Chung, S.L., Song, B., Liu, D., O'Reilly, S.Y., Pearson, N.J., Ji, J. and Wen, D.J., 2006. Zircon $\mathrm{U}-\mathrm{Pb}$ and $\mathrm{Hf}$ isotope constraints on the Mesozoic tectonics and crustal evolution of southern Tibet. Geology, 34, 745-748, doi: 10.1130/g22725.1.

Dai, J., Wang, C., Polat, A., Santosh, M., Li, Y. and Ge, Y., 2013. Rapid forearc spreading between 130 and 120Ma: evidence from geochronology and geochemistry of the Xigaze ophiolite, southern Tibet. Lithos, 172, 1-16, doi:10.1016/j.lithos.2013.03.011.

Dewey, J.F. and Bird, J.M., 1971. Origin and emplacement of the ophiolite suite: Appalachian ophiolites in Newfoundland. Journal of Geophysical Research, 76, 3179-3206, doi:10.1029/jb076i014p03179.

Dilek, Y., and Flower, F.J., 2003. Arc-trench rollback and forearc accretion: 2. A model template for ophiolites in Albania, Cyprus, and Oman, in Dilek, Y., and Robinson, P.T., eds, Ophiolites in Earth History, Geological Society, Special Publications, 218, 43-68.

Dilek, Y. and Furnes, H. 2014. Ophiolites and their origins. Elements, 10, 93-100, doi:10.2113/gselements.10.2.93.

Dilek, Y. and Furnes, H., 2009. Structure and geochemistry of Tethyan ophiolites and their petrogenesis in subduction rollback systems. Lithos, 113, 1-20, doi:10.1016/j.lithos.2009.04.022.

Dilek, Y. and Furnes, H., 2011. Ophiolite genesis and global tectonics: geochemical and tectonic fingerprinting of ancient oceanic lithosphere. Geological Society of America Bulletin, 123, 387-411, doi:10.1130/b30446.1.

Dubois-Côté, V., Hébert, R., Dupuis, C., Wang, C.S., Li, Y.L. and Dostal, J., 2005. Petrological and geochemical evidence for the origin of the Yarlung Zangbo ophiolites, southern Tibet. Chemical Geology, 214, 265-286, doi:10.1016/j.chemgeo.2004.10.004. 
Dürr, S.B., 1996. Provenance of Xigaze fore-arc basin clastic rocks (Cretaceous, south Tibet). Geological Society of America Bulletin, 108, 669-684.

Fullsack, P., 1995. An arbitrary Lagrangian-Eulerian formulation for creeping flows and applications in tectonic models. Geophysical Journal International, 120, 1-23, doi:10.1111/j.1365-246x.1995.tb05908.x.

Gerya, T.V. and Meilick, F.I., 2011. Geodynamic regimes of subduction under an active margin: effects of rheological weakening by fluids and melts. Journal of Metamorphic Geology, 29, 7-31.

Gleason, G.C. and Tullis, J., 1995. A flow law for dislocation creep of quartz aggregates determined with the molten salt cell. Tectonophysics, 247, 1-23, doi:10.1016/00401951(95)00011-b.

Gorczyk, W., Willner, A.P., Gerya, T.V., Connolly, J.A.D., Burg, J.-P., 2007. Physical controls of magmatic productivity at Pacific-type convergent margins: New insights from numerical modeling. Physics of the Earth and Planetary Interiors, 163, 209-232.

Griffin, W.L., Afonso, J.C., Belousova, E.A., Gain, S.E., Gong, X.H., González-Jiménez, J.M., Howell, D., Huang, J.X., McGowan, N., Pearson, N.J. and Satsukawa, T., 2016. Mantle Recycling: Transition Zone Metamorphism of Tibetan Ophiolitic Peridotites and its Tectonic Implications. Journal of Petrology, 57, 655-684, doi:10.1093/petrology/egw011.

Guilmette, C., Hébert, R., Dupuis, C., Wang, C. and Li, Z., 2008. Metamorphic history and geodynamic significance of high-grade metabasites from the ophiolitic mélange beneath the Yarlung Zangbo ophiolites, Xigaze area, Tibet. Journal of Asian Earth Sciences, 32, 423-437, doi:10.1016/j.jseaes.2007.11.013.

Guilmette, C., Hébert, R., Wang, C. and Villeneuve, M., 2009. Geochemistry and geochronology of the metamorphic sole underlying the Xigaze ophiolite, Yarlung Zangbo Suture Zone, south Tibet, Lithos, 112, 149-162, doi:10.1016/j.lithos.2009.05.027.

Hall, C.E., Gurnis, M., Sdrolias, M., Lavier, L.L. and Müller, R.D., 2003. Catastrophic initiation of subduction following forced convergence across fracture zones. Earth and Planetary Science Letters, 212, 15-30, doi:10.1016/s0012-821x(03)00242-5.

Hébert, R., Bezard, R., Guilmette, C., Dostal, J., Wang, C.S. and Liu, Z.F., 2012. The IndusYarlung Zangbo ophiolites from Nanga Parbat to Namche Barwa syntaxes, southern Tibet: first synthesis of petrology, geochemistry, and geochronology with incidences on geodynamic reconstructions of Neo-Tethys. Gondwana Research, 22, 377-397, doi:10.1016/j.gr.2011.10.013.

Huang, W., Van Hinsbergen, D.J., Maffione, M., Orme, D.A., Dupont-Nivet, G., Guilmette, C., Ding, L., Guo, Z. and Kapp, P., 2015. Lower Cretaceous Xigaze ophiolites formed in the 
Gangdese forearc: Evidence from paleomagnetism, sediment provenance, and stratigraphy. Earth and Planetary Science Letters, 415, 142-153, doi:10.1016/j.epsl.2015.01.032.

Ji, W.Q., Wu, F.Y., Chung, S.L., Li, J.X. and Liu, C.Z., 2009. Zircon U-Pb geochronology and Hf isotopic constraints on petrogenesis of the Gangdese batholith, southern Tibet. Chemical Geology, 262, 229-245, doi:10.1016/j.chemgeo.2009.01.020.

Karato, S-i. and Wu, P., 1993. Rheology of the upper mantle- A synthesis. Science, 260, 771778, doi:10.1126/science.260.5109.771.

Katayama. I., and Karato, S-i., 2008. Low-temperature, high-stress deformation of olivine under water-saturated conditions. Physics of the Earth and Planetary Interiors 168, 125133.

Kelly, S., Butler, J.P. and Beaumont, C., 2016. Continental collision with a sandwiched accreted terrane: Insights into Himalayan-Tibetan lithospheric mantle tectonics?. Earth and Planetary Science Letters, 455, 176-195, doi:10.1016/j.epsl.2016.08.039.

Korenaga, J., 2013. Initiation and evolution of plate tectonics on Earth: theories and observations. Annual Review of Earth and Planetary Sciences, 41, 117-151.

Leng, W. and Gurnis, M., 2011. Dynamics of subduction initiation with different evolutionary pathways. Geochemistry, Geophysics, Geosystems, 12, doi:10.1029/2011gc003877.

Ma, Y., Yang, T., Yang, Z., Zhang, S., Wu, H., Li, H., Li, H., Chen, W., Zhang, J. and Ding, J., 2014. Paleomagnetism and $\mathrm{U}-\mathrm{Pb}$ zircon geochronology of Lower Cretaceous lava flows from the western Lhasa terrane: New constraints on the India-Asia collision process and intracontinental deformation within Asia. Journal of Geophysical Research: Solid Earth, 119, 7404-7424, doi:10.1002/2014jb011362.

Mackwell, S.J., Zimmerman, M.E. and Kohlstedt, D.L., 1998. High-temperature deformation of dry diabase with application to tectonics on Venus. Journal of Geophysical Research: Solid Earth, 103, 975-984, doi:10.1029/97jb02671.

Maffione, M., Van Hinsbergen, D.J., Koornneef, L.M., Guilmette, C., Hodges, K., Borneman, N., Huang, W., Ding, L. and Kapp, P., 2015. Forearc hyperextension dismembered the south Tibetan ophiolites. Geology, 43, 475-478, doi:10.1130/g36472.1.

Malpas, J., Zhou, M.F., Robinson, P.T. and Reynolds, P.H., 2003. Geochemical and geochronological constraints on the origin and emplacement of the Yarlung Zangbo ophiolites, Southern Tibet. Geological Society, London, Special Publications, 218, 191-206, doi:10.1144/gsl.sp.2003.218.01.11. 
825

McGowan, N.M., Griffin, W.L., González-Jiménez, J.M., Belousova, E., Afonso, J.C., Shi, R., McCammon, C.A., Pearson, N.J. and O’Reilly, S.Y., 2015. Tibetan chromitites: Excavating the slab graveyard. Geology, 43, 179-182.

McKenzie, D., Jackson, J. and Priestley, K., 2005. Thermal structure of oceanic and continental lithosphere. Earth and Planetary Science Letters, 233, 337-349, doi:10.1016/j.epsl.2005.02.005.

Metcalf, R.V. and Shervais, J.W., 2008. Suprasubduction-zone ophiolites: Is there really an ophiolite conundrum? Geological Society of America Special Papers, 438, 191-222, doi:10.1130/2008.2438(07).

Nicolas, A., Girardeau, J., Marcoux, J., Dupre, B., Xibin, W., Yougong, C., Haixiang, Z. and Xuchang, X., 1981. The Xigaze ophiolite (Tibet): a peculiar oceanic lithosphere. Nature, 294, 414-417, doi:10.1038/294414a0.

Nikolaeva, K., Gerya, T.V. and Marques, F.O., 2010. Subduction initiation at passive margins: numerical modeling. Journal of Geophysical Research: Solid Earth, 115, doi:10.1029/2009jb006549.

Orme, D.A., Carrapa, B. and Kapp, P., 2015. Sedimentology, provenance and geochronology of the upper Cretaceous-lower Eocene western Xigaze forearc basin, southern Tibet. Basin Research, 27, 387-411, doi:10.1111/bre.12080.

Pearce, J.A., Lippard, S.J. and Roberts, S., 1984. Characteristics and tectonic significance of supra-subduction zone ophiolites. Geological Society, London, Special Publications, 16, 7794, doi:10.1144/gsl.sp.1984.016.01.06.

Pearce, J.A., 2003. Supra-subduction zone ophiolites: the search for modern analogues. Special Papers-Geological Society of America, 373, 269-294, doi:10.1130/0-8137-23736.269.

Pearce, J.A., 2014. Immobile element fingerprinting of ophiolites. Elements, 10, 101-108, doi:10.2113/gselements.10.2.101.

Robinson, P.T., Bai, W.J., Malpas, J., Yang, J.S., Zhou, M.F., Fang, Q.S., Hu, X.F., Cameron, S. and Staudigel, H., 2004. Ultra-high pressure minerals in the Luobusa Ophiolite, Tibet, and their tectonic implications. Geological Society, London, Special Publications, 226, 247-271.

Royden, L.H., 1993. The tectonic expression slab pull at continental convergent boundaries, Tectonics, 12, 303-325.

Reagan, M.K., Ishizuka, O., Stern, R.J., Kelley, K.A., Ohara, Y., Blichert-Toft, J., Bloomer, S.H., Cash, J., Fryer, P., Hanan, B.B. and Hickey-Vargas, R., 2010. Fore-arc basalts and subduction initiation in the Izu-Bonin-Mariana system. Geochemistry, Geophysics, Geosystems, 11, doi:10.1029/2009gc002871. 
Sleep, N. and Toksöz, M.N., 1971. Evolution of marginal basins. Nature, 233, 548-550, doi:10.1038/233548a0.

Stefan, M., 1874. Experiments on apparent adhesion. Philosophical Magazine Series 4, 47, 465-466, doi:10.1080/14786447408641062.

Stern, R.J., 2004. Subduction initiation: spontaneous and induced. Earth and Planetary Science Letters, 226, 275-292, doi:10.1016/s0012-821x(04)00498-4.

Stern, R.J., Reagan, M., Ishizuka, O., Ohara, Y. and Whattam, S., 2012. To understand subduction initiation, study forearc crust: To understand forearc crust, study ophiolites. Lithosphere, 4, 469-483.

Stern, R.J. and Bloomer, S.H., 1992. Subduction zone infancy: examples from the Eocene IzuBonin-Mariana and Jurassic California arcs. Geological Society of America Bulletin, 104, 1621-1636.

Shervais, J.W., 2001. Birth, death, and resurrection: The life cycle of suprasubduction zone ophiolites. Geochemistry, Geophysics, Geosystems, 2, doi:10.1029/2000gc000080.

van Hinsbergen, D.J., Peters, K., Maffione, M., Spakman, W., Guilmette, C., Thieulot, C., Plümper, O., Gürer, D., Brouwer, F.M., Aldanmaz, E. and Kaymakcl, N., 2015. Dynamics of intraoceanic subduction initiation: 2. Suprasubduction zone ophiolite formation and metamorphic sole exhumation in context of absolute plate motions. Geochemistry, Geophysics, Geosystems, 16, 1771-1785.

Vogt, K., Gerya, T.V. and Castro, A., 2012. Crustal growth at active continental margins: numerical modeling. Physics of the Earth and Planetary Interiors, 192, 1-20.

Wang, C., Ding, L., Zhang, L.Y., Kapp, P., Pullen, A. and Yue, Y.H., 2016. Petrogenesis of Middle-Late Triassic volcanic rocks from the Gangdese belt, southern Lhasa terrane: Implications for early subduction of Neo-Tethyan oceanic lithosphere. Lithos, 262, 320333.

Warren, C.J., C. Beaumont, and Jamieson R.A., 2008. Deep subduction and rapid exhumation: Role of crustal strength and strain weakening in continental subduction and ultrahigh-pressure rock exhumation, Tectonics, 27, TC6002, doi:10.1029/2008TC002292.

Whattam, S.A. and Stern, R.J., 2011. The 'subduction initiation rule': a key for linking ophiolites, intra-oceanic forearcs, and subduction initiation. Contributions to Mineralogy and Petrology, 162, 1031-1045, doi:10.1007/s00410-011-0638-z.

Wu, F.Y., Ji, W.Q., Liu, C.Z. and Chung, S.L., 2010. Detrital zircon U-Pb and Hf isotopic data from the Xigaze fore-arc basin: constraints on Transhimalayan magmatic evolution in southern Tibet. Chemical Geology, 271, 13-25, doi:10.1016/j.chemgeo.2009.12.007. 
Xia, B., Yu, H.X., Chen, G.W., Qi, L., Zhao, T.P. and Zhou, M.F., 2003. Geochemistry and tectonic environment of the Dagzhuka ophiolite in the Yarlung-Zangbo suture zone, Tibet. Geochemical Journal, 37, 311-324, doi:10.2343/geochemj.37.311.

Xiong, Q., Griffin, W.L., Zheng, J.P., O'Reilly, S.Y., Pearson, N.J., Xu, B. and Belousova, E.A., 2016. Southward trench migration at 130-120 Ma caused accretion of the Neo-Tethyan forearc lithosphere in Tibetan ophiolites. Earth and Planetary Science Letters, 438, 57-65, doi:10.1016/j.epsl.2016.01.014.

Yamamoto, S., Komiya, T., Hirose, K. and Maruyama, S., 2009. Coesite and clinopyroxene exsolution lamellae in chromites: In-situ ultrahigh-pressure evidence from podiform chromitites in the Luobusa ophiolite, southern Tibet. Lithos, 109, 314-322, doi:10.1016/j.lithos.2008.05.003.

Yang, T., Ma, Y., Zhang, S., Bian, W., Yang, Z., Wu, H., Li, H., Chen, W. and Ding, J., 2015. New insights into the India-Asia collision process from Cretaceous paleomagnetic and geochronologic results in the Lhasa terrane. Gondwana Research, 28, 625-641, doi:10.1016/j.gr.2014.06.010.

Yang, J.S., Robinson, P.T. and Dilek, Y., 2014. Diamonds in ophiolites. Elements, 10, 127130, doi:10.2113/gselements.10.2.127.

Yang, J.S., Dobrzhinetskaya, L., Bai, W.J., Fang, Q.S., Robinson, P.T., Zhang, J. and Green, H.W., 2007. Diamond- and coesite-bearing chromitites from the Luobusa ophiolite, Tibet. Geology, 35, 875-878, doi:10.1130/g23766a.1.

Ziabrev, S., Aitchison, J., Abrajevitch, A., Davis, A. and Luo, H., 2003. Precise radiolarian age constraints on the timing of ophiolite generation and sedimentation in the Dazhuqu terrane, Yarlung-Tsangpo suture zone, Tibet. Journal of the Geological Society, 160, 591599, doi:10.1144/0016-764902-107.

Zhu, D-C., Zhao, Z-D., Pan, G-T, Lee, H-Y., Kang, Z-Q., Liao, Z-L., Wang, L-Q., Li, G-M., Dong, GC., Liu, B., 2009. Early cretaceous subduction-related adakite-like rocks of the Gangdese Belt, southern Tibet: Products of slab melting and subsequent melt-peridotite interaction? Journal of Asian Earth Sciences 34 (2009) 298-309.

Zhu, D.C., Zhao, Z.D., Niu, Y., Mo, X.X., Chung, S.L., Hou, Z.Q., Wang, L.Q. and Wu, F.Y., 2011. The Lhasa Terrane: record of a microcontinent and its histories of drift and growth. Earth and Planetary Science Letters, 301, 241-255, doi: 


\section{Figure and table captions}

Figure 1: Design of two-dimensional models (see Section 2 and Appendix 1 for more details). The full model $4000 \times 1200 \mathrm{~km}$ domain is represented by a coarse computational grid with a maximum resolution of $10 \times 2 \mathrm{~km}$. A higher-resolution, 'nested' computational grid (dashed line) is embedded within the coarse grid in the vicinity of the subduction zone and retro-lithosphere, and has a maximum resolution of $2 \times 2 \mathrm{~km}$. CLM = continental lithospheric mantle, OLM = oceanic lithospheric mantle, SLM = sub-lithospheric mantle, LM = lower mantle. Forearc OLM (orange) appears in subsequent figures, formed by cooling of sub-lithospheric mantle. Black arrows show velocity boundary conditions in schematic form. Red shows thermal boundary conditions (basal heat flux) and resulting surface heat flux and continental temperatures. WQ = wet quartzite, DMD = dry Maryland diabase, WOL $=$ wet olivine. $\phi=$ range of effective angle of internal friction ( $\left.\phi_{\text {eff }}\right)$ owing to pore-fluid pressure and frictional-plastic strain-softening; $\mathrm{A}=$ radiogenic heat production $\left(\mu \mathrm{W} \mathrm{m} \mathrm{m}^{-3}\right)$ $\left(A_{R}\right.$ in text); $\rho=$ density (Table 1$)$.

Figure 2: Model template. Models test the depletion of the oceanic lithospheric mantle $\left(\Delta \rho_{\text {OLM }}\right)$ versus oceanic sediment viscous strength $\left(f_{\text {sed }}\right)$. Three regimes are identified (Section 3): $\mathrm{R}$ = subduction zone retreat; $\mathrm{C}=$ coupled subduction; $\mathrm{B}=$ slab break-off followed by either coupled subduction (B-C), or retreat (B-R). Panels indicate timing of subduction zone decoupling $\left(t_{D}\right)$, and of break-off $\left(t_{B}\right)$ where applicable. In decoupling cases the pro-lithosphere tensile tectonic force $\left(F_{D}\right)$ required for subduction zone decoupling is also given (in $\mathrm{GN} \mathrm{m}^{-1}$ ). BA-B-R is the model with backarc rifting.

Figure 3: Model FA-C results $\left(\Delta \rho_{O L M}=30 ; f_{\text {sed }}=0.5\right)(\mathrm{a}-\mathrm{c})$ Material colors (see Fig. 1$)$ and isotherms $\left(100^{\circ} \mathrm{C}\right.$ and then at $200^{\circ} \mathrm{C}$ increments) for selected model times. Orange at base of retro-lithosphere at start of model represents a small amount of cooled sub-lithospheric mantle that has become lithosphere. $t=$ model time, $\Delta x$ is the convergence (see text for definition); arrows show velocities. Insets show subduction zone in more detail. (d) Proand retro-lithosphere horizontal tectonic boundary forces (total force - pressure) (blue and green, respectively), note sign convention, tension is positive.

Figure 4: Model FA-R results, $\left(\Delta \rho_{O L M}=20 ; \mathrm{f}_{\mathrm{sed}}=0.3\right)(\mathrm{a}-\mathrm{d})$ Material colors (see Fig. 1) and isotherms $\left(100^{\circ} \mathrm{C}\right.$ and then at $200^{\circ} \mathrm{C}$ increments, $400^{\circ} \mathrm{C}$ increments in panels $\mathrm{c}$ and $\mathrm{d}$ for clarity)for selected model times. Insets show subduction zone in more detail. Orange at base of retro-lithosphere at start of model represents a small amount of cooled sublithospheric mantle that has become lithosphere and increases as forearc basin lithosphere develops. $t=$ model time, $\Delta x$ is the convergence (see text for definition); arrows show velocities. (e) Pro- and retro-lithosphere horizontal tectonic boundary forces (total force pressure) (blue and green, respectively. (f) Enlarged inset from panel b showing detail of exhumed material during subduction zone decoupling (see material legend).

Figure 5: Model FA-B-R results, $\left(\Delta \rho_{O L M}=20 ; \mathrm{f}_{\mathrm{sed}}=0.5\right)(\mathrm{a}-\mathrm{d})$ Material colors (see Fig. 1) and isotherms $\left(100^{\circ} \mathrm{C}\right.$ and then at $200^{\circ} \mathrm{C}$ increments $\left(400^{\circ} \mathrm{C}\right.$ increments in panel e for clarity)) for selected model times. Insets show subduction zone in more detail. Orange at base of retro-lithosphere at start of model represents a small amount of cooled sub- 
lithospheric mantle that has become lithosphere and increases as forearc basin lithosphere develops. Second inset in panel d shows alternative Model BA-B-R, where rifting develops in the back-arc, not forearc (see text). $t=$ model time, $\Delta x$ is the convergence (see text for definition); arrows show velocities. (e) Pro- and retro-lithosphere horizontal tectonic boundary forces (total force -pressure) (blue and green, respectively).

Figure 6: Steps in subduction zone decoupling and retreat for Model FA-R, $\left(\Delta \rho_{O L M}=20 ; f_{\text {sed }}\right.$ $=0.3$ ). (a) Distribution of frictional-plastic on yield material (red; yellow on verge of failure) and viscous material (blue), isotherms (white) $\left(100^{\circ} \mathrm{C}\right.$ and then at $200^{\circ} \mathrm{C}$ increments). (b-e) Effective viscosity distribution and isotherms (white) $\left(100^{\circ} \mathrm{C}\right.$ and then at $200^{\circ} \mathrm{C}$ increments) for selected model times. $t=$ model time, $\Delta x$ is the convergence (see text for definition); arrows show velocities. (f) Pro- and retro-lithosphere horizontal tectonic boundary forces (total force -pressure) (blue and green, respectively) during decoupling, note sign convention, tension is positive.

Figure 7: Comparison of evolution of the Xigaze group ophiolites with numerical model results. (a) Simplified geological timeline showing relevant events in evolution of the Lhasa terrane/Xigaze forearc system. (b-f) Inferred evolution of Neo-Tethyan subduction beneath the Lhasa terrane and opening of the Xigaze forearc ocean basin (see Section 5 for details), based in part on the interpretation of Dai et al. (2013). Dashed lines link panels b-f to timeline in a. Bold lines denote possible evolution of the system which may or may not have involved a slab break-off prior to the onset of forearc ocean spreading (see text). (g-i) Selected frames from Model FA-B-R corresponding to inferred geological evolution.

Figure 8: Results for models FA-R-EX1 and FA-R-EX2 showing mantle flow and exhumation of tracking blocks (initial positions of blocks shown in insets).(a,b) Material colors (see Fig. 1) and isotherms $\left(100^{\circ} \mathrm{C}\right.$ and then at $200^{\circ} \mathrm{C}$ increments) for selected model times chosen to show significant developments in Model FA-R-EX1. $\Delta x$ is the convergence; arrows show velocities. Time is given in normal model time for inset in panel a (prior to onset of retreat), and as $\Delta t_{D}$ (time since the onset of subduction zone retreat at $8 \mathrm{Myr}$ ) for subsequent panels. (c) Maximum pressures achieved by model materials showing exhumation of ultrahigh-pressure material into the forearc ocean basin. Isotherms in e and f are plotted at $100^{\circ} \mathrm{C}$ and then at $400^{\circ} \mathrm{C}$ increments. (d-f) Corresponding panels for Model FA-R-EX2, with variably depleted tracking blocks (scale below panel e). See Supplementary Figures S1 and S2 for model output at $\Delta t_{D}=9.5 \mathrm{Myr}$. 
Table 1:

1050

Material and geometrical parameters used in model experiments. RC = retro-continent.

1051 Flow laws are dry Maryland diabase (DMD; Mackwell et al., 1998), wet olivine (WOL;

1052

1053

1054

1055

1056

1057

1058

1059

1060

1061

1062

1063

1064

1065

1066

1067

1068

1069

1070

1071

1072

1073

1074

1075

1076

1077

1078

1079 


\section{Appendix}

1102 A1. Modeling Methods

\section{A1.1 Overview of SOPALE-nested code}

We use two-dimensional thermomechanical models computed using the software SOPALEnested (Fullsack, 1995; Beaumont et al., 2009; Butler et al. 2014) to investigate the dynamics of active continental margins at the upper-mantle and part lower-mantle-scale. The models are designed based on a simple geometry representing oceanic subduction beneath a continental margin. The methodology remains similar to our recent work (Beaumont et al., 2009; Butler et al., 2014; Kelly et al., 2016).

The models are computed by solving the equations for incompressible creeping (Stokes) flows (Eqs. A.1 and A.2) and energy balance (Eq. A.3) subject to mechanical and thermal boundary conditions:

(Eq. A.1) $\quad \frac{\partial \sigma_{i j}}{\partial x_{i}}-\frac{\partial P}{\partial x_{i}}+\rho g=0, \quad i, j=1,2$

(Eq. A.2) $\quad \frac{\partial v_{i}}{\partial x_{i}}=0, \quad i=1,2$

(Eq. A.3)

$$
\rho(T) c_{p}\left(\frac{\partial T}{\partial t}+v_{i} \frac{\partial T}{\partial x_{i}}\right)=\frac{\partial}{\partial x_{i}} K(T) \frac{\partial T}{\partial x_{i}}+A_{R}+A_{S H}+v_{2} \alpha g T \rho(T), \quad i=1,2,
$$

where $\sigma_{i j}$ is the deviatoric stress tensor, $x_{i}$ spatial coordinates, $P$ pressure (mean stress), $\rho$ density, $g$ gravitational acceleration, $v_{i}$ a component of velocity, $c_{p}$ specific heat, $T$ temperature, $t$ time, $K(T)$ thermal conductivity (see Section A1.3), $A_{R}$ crustal radioactive heat production per unit volume, $A_{S H}$ shear heating, and $\alpha$ volumetric thermal expansivity. Coupling of the mechanical and thermal solutions results from the advection of radioactive crust, shear heating, thermal activation of viscous flow, and buoyancy forces arising from metamorphic phase changes and thermal expansion.

The models use a sub-grid method in which a higher-resolution computational domain is 'nested' within a larger, lower-resolution domain. The velocity and thermal solution is first obtained for the full domain. This solution is then interpolated onto the boundaries of the nested domain, here encompassing the vicinity of the subduction zone. Coupling of the grids is maintained by using a single cloud of Lagrangian tracking particles, which is passed between the two solutions, with the particles within the nested domain 
1129 always obeying the higher resolution solution.

\section{$1130 \quad$ A1.2 Model geometry and boundary conditions}

1131 The model domain is $4000 \mathrm{~km}$ wide by $1200 \mathrm{~km}$ deep. The initial configuration (Fig. 1,

1132 Table 1) represents a simplified active continental margin subduction system comprising

1133 an oceanic pro-lithosphere and continental retro-lithosphere, overlying upper mantle to

1134 depth of $660 \mathrm{~km}$ and then lower mantle to $1200 \mathrm{~km}$. The $100 \mathrm{Myr}$-old oceanic lithosphere

1135 is 100-km thick, comprising $3 \mathrm{~km}$ sediment, $6 \mathrm{~km}$ oceanic crust, and $91 \mathrm{~km}$ lithospheric

1136 mantle of which the upper $51 \mathrm{~km}$ (i.e., to a depth of $60 \mathrm{~km}$ ) is chemically depleted and has

1137 lower density to represent the effect of decompression melting. The 120 -km thick retro-

1138 continent comprises an upper $10 \mathrm{~km}$-thick weak layer, $14 \mathrm{~km}$ normal upper crust, $12 \mathrm{~km}$

1139 lower crust, and $84 \mathrm{~km}$ lithospheric mantle (Table 1).

1140 Subduction is initiated at the location of a weak seed embedded in the retro-

1141 lithosphere at the boundary between oceanic lithosphere and retro-continent (Fig.1). The

1142 boundary conditions applied to the models comprise pro-lithospheric convergence velocity

$1143 V_{p}=5 \mathrm{~cm} \mathrm{a}^{-1}$ on the left lithospheric boundary and retro-lithospheric velocity, $V_{r}=0 \mathrm{~cm} \mathrm{a}^{-1}$

1144 on the right boundary. Small sub-lithospheric boundary fluxes are used to 'pump' material

1145 out of the sides of the model to conserve volume and maintain isostatic equilibrium. The

1146 sides and base of the model domain have no-slip boundary conditions. The top of the model

1147 is a free surface but subject to water loading in oceanic regions. Thermal boundary

1148 conditions include a basal heat flux of $21 \mathrm{~mW} \mathrm{~m}^{-2}, 0^{\circ} \mathrm{C}$ surface, and insulated side

1149 boundaries. The initial temperature regime corresponds to 2D thermal steady state.

\section{$1150 \quad$ A1.3 Material properties}

1151 The material properties and flow laws are similar to those used in Beaumont

1152 et al. (2001), and Butler et al. (2013); see Butler et al. (2014) for detailed justification of

1153 flow laws and their scaling. The model parameter values are typical of continental and

1154 oceanic lithospheric materials (Beaumont et al., 2006, and refs. therein).

1155 Model materials deform by either frictional-plastic (brittle) or viscous (ductile) flow

1156 that includes additional strain-softening/strain-weakening mechanisms. Brittle

1157 deformation is modeled using the frictional-plastic Drucker-Prager yield criterion, $\sigma_{y}$ :

$1158 \quad$ (Eq. A.4) $\sigma_{y}=\left(J_{2}^{\prime}\right)^{1 / 2}=P \sin \phi_{\mathrm{eff}}+C \cos \phi_{\mathrm{eff}}$ 
where $J_{2}^{\prime}$ is the second invariant of the deviatoric stress, $P$ dynamical pressure (mean

1160

1161

1162

1163

1164

1165

1166

1167

1168

1169

1170

1171

1172

1173

1174

1175

1176

1177

1178

1179

1180

1181

1182

1183

1184

1185

1186

1187 stress), and $C$ cohesion. The effective angle of internal friction, $\phi_{\text {eff, }}$ is defined to include the effects of pore fluid pressure. Ductile deformation is modeled using power-law flow, for which the effective viscosity is:

(Eq. A.5) $\quad \eta_{\mathrm{eff}}^{v}=\frac{f}{W_{S}} A^{-1 / n}{\dot{I_{2}^{\prime}}}^{(1-n) / 2 n} \exp \left(\frac{Q+P V^{*}}{n R T_{K}}\right)$

where $f$ is a viscosity scaling factor, $W_{s}$ a strain-weakening factor, $A$ the pre-exponential factor, converted to the tensor invariant form, $\dot{I}_{2}$ the second invariant of the deviatoric strain rate, $n$ the stress exponent, $Q$ activation energy, $V^{*}$ the activation volume for powerlaw creep, $T_{K}$ absolute temperature, and $R$ universal gas constant. For simplicity, we base the model materials on a small set of laboratory-determined flow laws (see below; Table 1).

If the deviatoric stress in the oceanic mantle lithosphere reaches a high stress limit, the Peierls stress, $\sigma_{p}$, a new rheology dominates where the viscosity has an exponential dependence on stress (Katayama and Karato, 2008). SOPALE-nested models this rheological law by effectively limiting the calculated stress at, $\sigma_{p}$, by downscaling the viscosity so that the stress does not exceed the Peierls stress (100 MPa) for oceanic lithospheric mantle.

Crustal materials and the lithospheric mantle soften/weaken in the frictional-plastic and viscous regimes, respectively. Frictional-plastic materials strain-soften through a linear decrease in their effective angle of internal friction, $\phi_{\mathrm{eff}}$, with accumulated strain: $\phi_{\mathrm{eff}}=$ $\phi_{\mathrm{eff}}(\varepsilon) ; \varepsilon=I_{2}^{\prime 1 / 2}$, the square root of the second invariant of deviatoric strain, termed $\varepsilon$

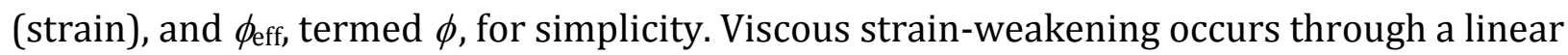
decrease in effective viscosity by the factor $W_{s}$ over a specified $\varepsilon$ range. For all models, crustal materials weaken by $W_{s}=10$ over the range $\varepsilon=5-10$. The exception is the oceanic sediment, which does not strain weaken, but has $f$-values $\left(f_{\text {sed }}\right)$ which vary among experiments. Strain-weakening and softening as implemented in our models depends on the resolution of the computational grid $(2 \times 2 \mathrm{~km}$ in the nested region). Given that natural shear zones form at finer scales, equivalent natural strain weakening/softening occurs at smaller offsets across shear zones because the shear zones are narrower than the typical 6 
$1188 \mathrm{~km}$ in these models. It follows that the model materials weaken/soften more slowly than 1189 ones would with higher resolution. By implication, higher resolution models will give 1190 equivalent results with proportionally larger values of the minimum $\phi_{\mathrm{eff}}$, and smaller values 1191 of $W_{s}$. The values used here should therefore be interpreted as minimum and maximum 1192 values, respectively. Model material parameters are given in Table 1 . Oceanic sediment has $\phi=8-2^{\circ}$ and a wet quartzite (WQ; Gleason and Tullis, 1995) flow law scaled by $f_{\text {sed, which varies among }}$ 1195 experiments from $f=0.1,0.3,0.5$, and 1 . The underlying oceanic crust has $\phi=15-2^{\circ}$ and a 1196 dry Maryland diabase (DMD; Mackwell et al., 1998) flow law with $f=0.1$. The oceanic 1197 lithospheric mantle has $\phi=15-2^{\circ}$ and a wet olivine (WO; Karato and Wu, 1993) flow law 1198 with $f=3$, representing somewhat 'dryer' conditions than the underlying mantle. The retro1199 continent upper crust comprises two layers. The upper $10 \mathrm{~km}$ of crust has $\phi=8-2^{\circ}$ and a 1200 WQ, $f=1$ flow law. The underlying $14 \mathrm{~km}$ of upper crust is somewhat stronger, with $\phi=$ $120115-2^{\circ}$ and $\mathrm{WQ}, f=5$. The retro-continent lower crust has $\phi=15-2^{\circ}$ and a DMD, $f=0.5$ flow 1202 law. The retro-continent lithospheric mantle has $\phi=15-2^{\circ}$, and a WO, $f=10$ flow law, 1203 representing dehydrated 'dry' lithosphere. The upper mantle sub-lithospheric mantle has $\phi$ $1204=15-2^{\circ}$ and a WOL, $f=2$ flow law. Owing to considerable uncertainty in the rheology of the 1205 lower mantle (e.g., Billen, 2010), we assume that the lower mantle has a constant/uniform 1206 viscosity of $1 \times 10^{21} \mathrm{~Pa}$ s. The $660-\mathrm{km}$-deep upper to lower mantle boundary corresponds to 1207 a dynamical phase change boundary across which density increases by $\sim 8 \%$, and the 1208 viscosity changes from power-law creep to constant linear viscosity. The retro-continent has crustal radioactive heat production $\left(A_{R}, A\right.$ in Fig. 1$)$ for the 1211 thermal boundary conditions, the resulting initial steady state surface heat flow and Moho 1212 temperatures for the continent are $62 \mathrm{mWm}^{-2}$ and $\sim 600^{\circ} \mathrm{C}$. The initial base lithosphere 1213 temperature throughout the model is $\sim 1350^{\circ} \mathrm{C}$. The thermal conductivity of the 1214 lithospheric and sub-lithospheric mantle varies with temperature per experimental 1215 constraints on olivine (e.g., McKenzie et al., 2005). Specifically, the thermal conductivity 1216 varies linearly from $5-2.4 \mathrm{~W} \mathrm{~m}^{-1} \mathrm{~K}^{-1}$ over the temperature range 273-1050 K. Similarly, the 
1217 mantle thermal expansion coefficient varies linearly with temperature from $3.2-3.9 \mathrm{~K}^{-1}$

1218 over temperature range 500-2000 K.

1219 A1.4 Density, volume and mass conservation during phase transitions

1220 Crustal materials undergo pressure- and temperature-dependent density changes

1221 corresponding to the eclogite and coesite-eclogite phase transitions as described by

1222 Warren et al. (2008) with values given in Table 1, and reverse during exhumation. Basaltic

1223 oceanic crust (density $2950 \mathrm{~kg} \mathrm{~m}^{-3}$ ) transforms to eclogite (density $3400 \mathrm{~kg} \mathrm{~m}^{-3}$ ). Oceanic

1224 sediment transforms from a density of $2800 \mathrm{~kg} \mathrm{~m}^{-3}$ to $2900 \mathrm{~kg} \mathrm{~m}^{-3}$ and then $3370 \mathrm{~kg} \mathrm{~m}^{-3}$ at

1225 HP and UHP conditions, respectively. Mantle materials undergo a similar process involving

1226 an $\sim 8 \%$ density increase at $660 \mathrm{~km}$ depth. During these phase changes the

1227 incompressibility equation is modified to that of mass conservation: $\partial \rho / \partial t=-\partial\left(\rho v_{i}\right) / \partial x_{i}$.

1228 This accounts for the volume change and its effect on the buoyancy and velocity field. The

1229 volume change is imposed numerically by applying additional normal,

1230 compressive/dilatational forces to finite elements at the time they are subject to phase-

1231 related density changes. The value of the excess pressure is $\Delta P=\Delta \rho / \beta_{v} \rho$, where $\beta_{v}$ is the

1232 viscous bulk modulus of the material, and $\Delta \rho / \rho$ is the fractional change in density

1233 corresponding to the phase change. The excess pressure compresses material locally and

1234 only during the model time steps when the phase changes occur, thereby ensuring mass

1235 conservation. The fractional volume change accompanying a phase change is small in these

1236 models and its effect on the velocity field is minor because it only applies at the time of the

1237 phase change. However, failure to ensure mass conservation would have a long-term effect

1238 on the model because the buoyancy forces will be over- or under-estimated by the

1239 fractional error in the material volume. 


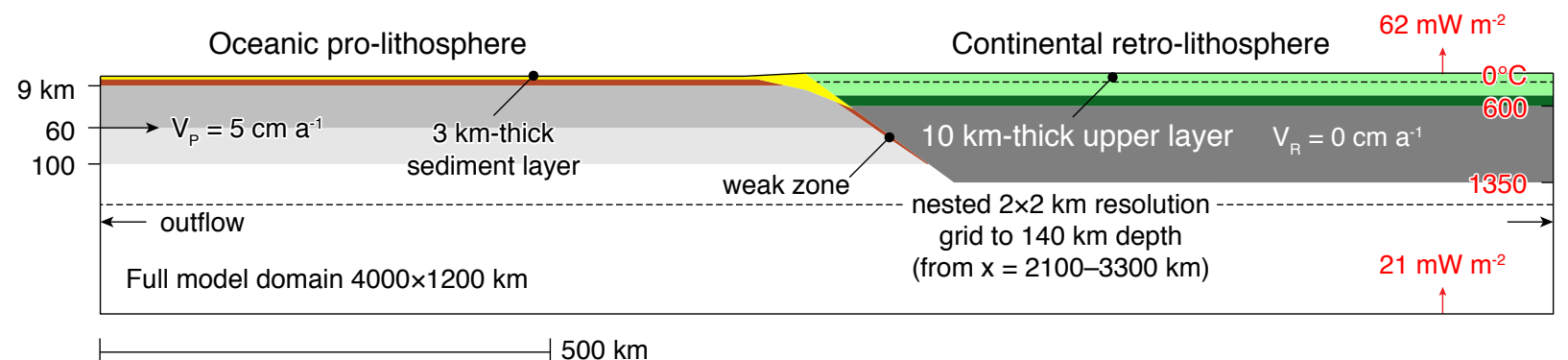

\section{Oceanic pro-lithosphere}

$\square$ sediment (WQxf ${ }_{\text {sed }}, \phi=8-2^{\circ}, A=1.0, \rho=2800 \mathrm{~kg} \mathrm{~m}^{-3}$ )

oceanic crust (DMD $\times 0.1, \phi=15-2^{\circ}, A=0, \rho=2950 \mathrm{~kg} \mathrm{~m}^{-3}$ )

$\square$ OLM (depleted) (WOL $\times 3, \phi=15-2^{\circ}, A=0, \rho=$ variable)

$\square$ OLM (WOL $\times 3, \phi=15-2^{\circ}, A=0, \rho=3370 \mathrm{~kg} \mathrm{~m}^{-3}$ )

Forearc OLM (WOL $\times 3, \phi=15-2^{\circ}, A=0$, $\rho=3340 \mathrm{~kg} \mathrm{~m}^{-3}\left(3370 \mathrm{~kg} \mathrm{~m}^{-3}\right.$ below $\left.\left.60 \mathrm{~km}\right)\right)$

\section{Continental retro-lithosphere}

upper crust $\left(\mathrm{WQ} \times 5, \phi=15-2^{\circ}\left(\mathrm{WQ} \times 1,8-2^{\circ}\right.\right.$ in upper $\left.10 \mathrm{~km}\right)$, $\left.\mathrm{A}=1.5, \rho=2800 \mathrm{~kg} \mathrm{~m}^{-3}\right)$

lower crust (DMD $\times 0.5, \phi=15-2^{\circ}, A=0.4, \rho=2900 \mathrm{~kg} \mathrm{~m}^{-3}$ )

CLM (WOL $\times 10, \phi=15-2^{\circ}, A=0, \rho=3340 \mathrm{~kg} \mathrm{~m}^{-3}$ )

SLM (WOL $\left.\times 2, \phi=15-2^{\circ}, A=0, \rho=3370 \mathrm{~kg} \mathrm{~m}^{-3}\right)$

$\operatorname{LM}\left(10^{21} \mathrm{~Pa} \mathrm{~s}, \phi=15-2^{\circ}, \mathrm{A}=0, \rho=3630 \mathrm{~kg} \mathrm{~m}^{-3}\right)$ 


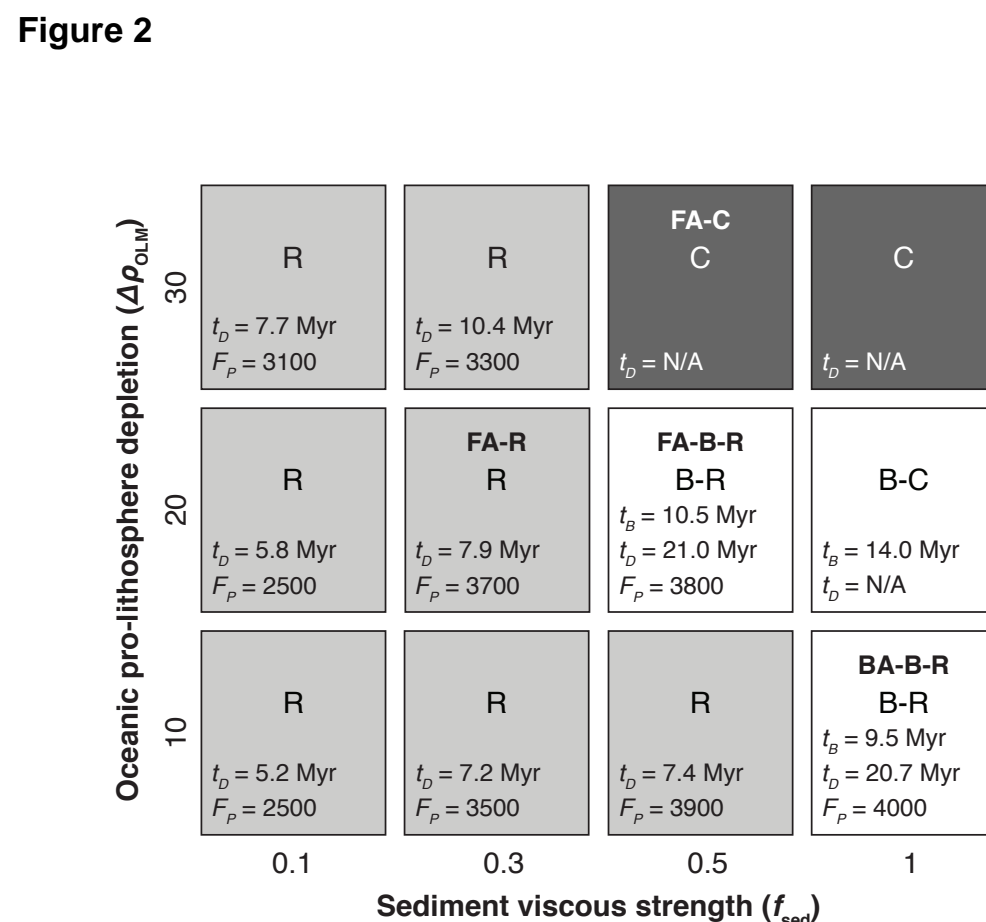

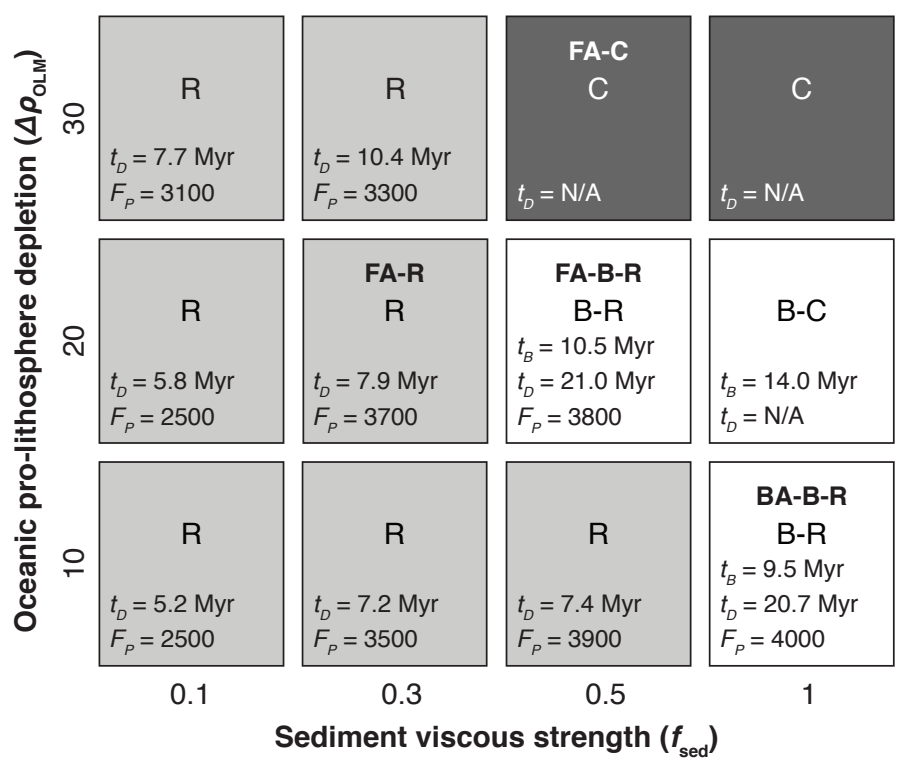

-

$$
\text { ( }
$$


(a) Model FA-C; $t=3.0 \mathrm{Myr} ; \Delta \mathrm{x}=150 \mathrm{~km}$

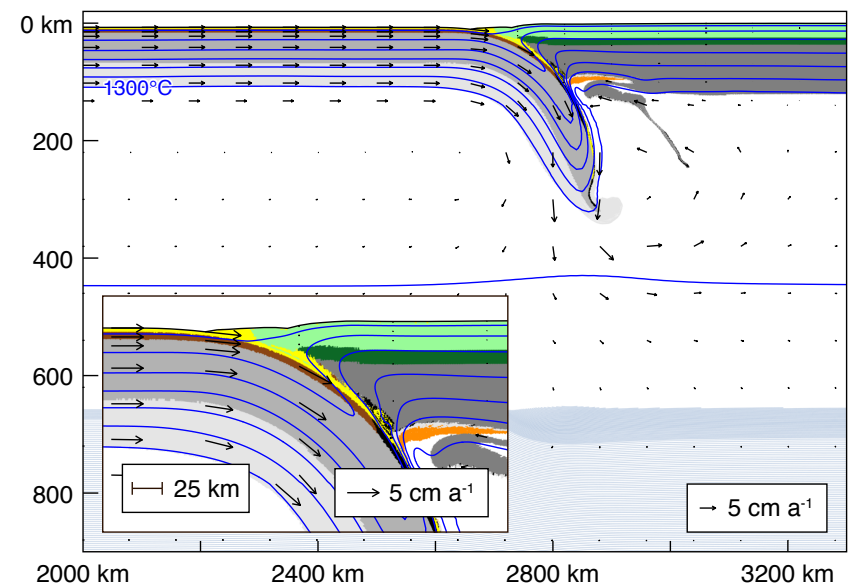

(c) Model FA-C; t $=15.5 \mathrm{Myr} ; \Delta x=495 \mathrm{~km}$

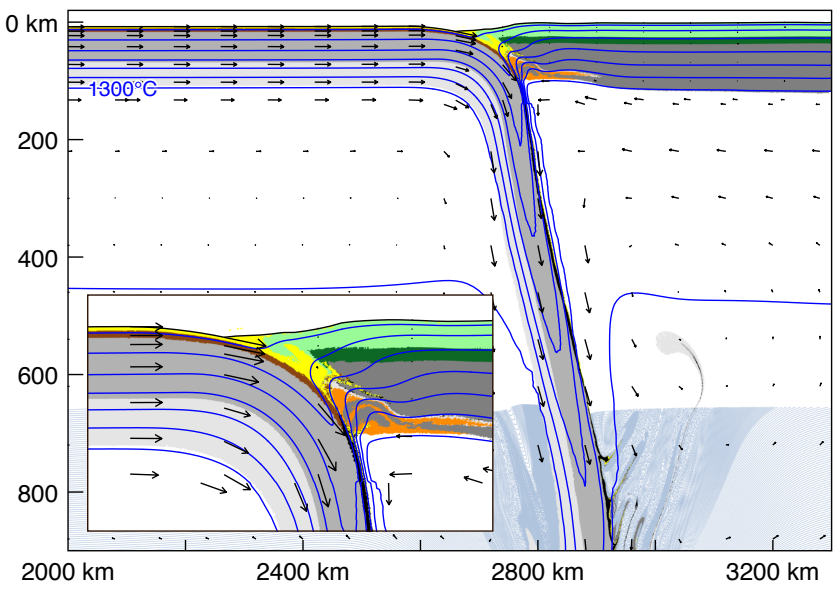

(b) Model FA-C; $t=6.5 \mathrm{Myr} ; \Delta x=195 \mathrm{~km}$

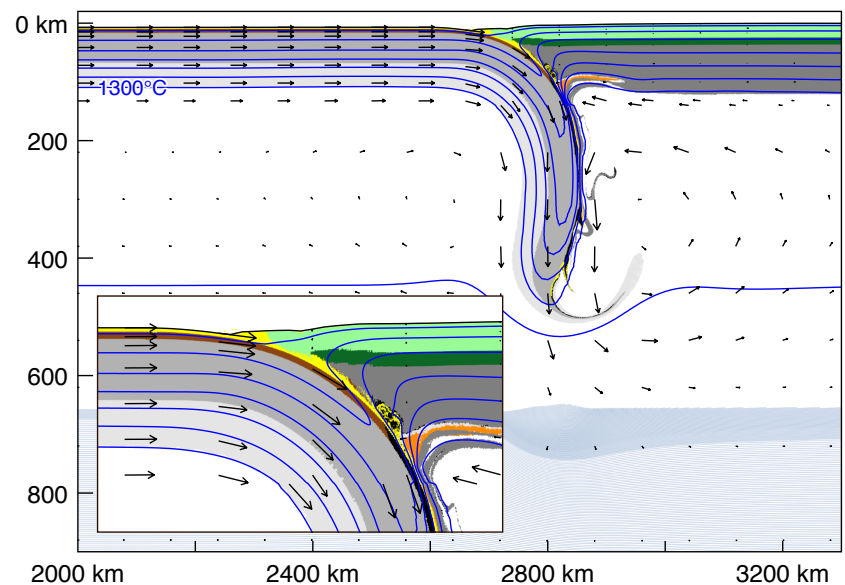

(d) Model FA-C; Tectonic forces

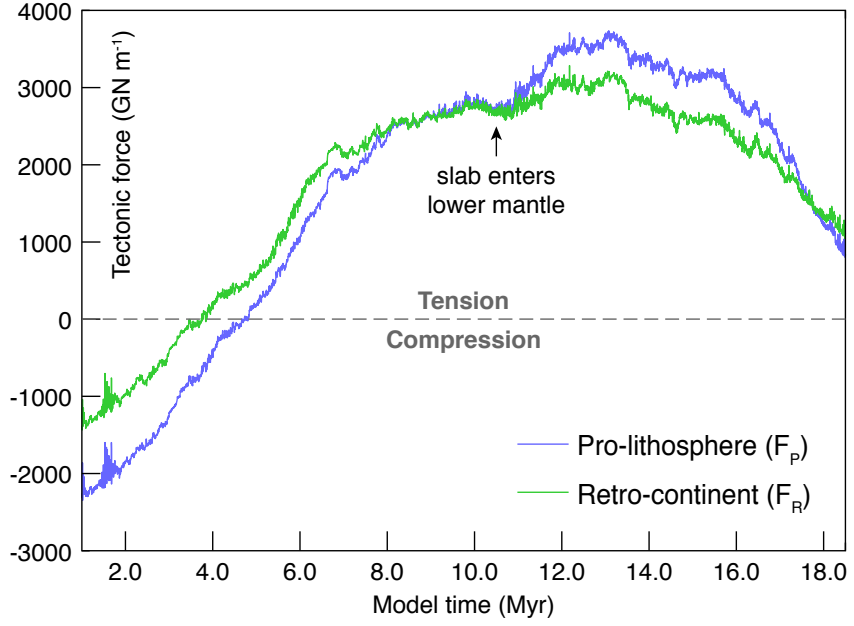


(a) Model FA-R; $t=6.5 \mathrm{Myr} ; \Delta \mathrm{x}=325 \mathrm{~km}$

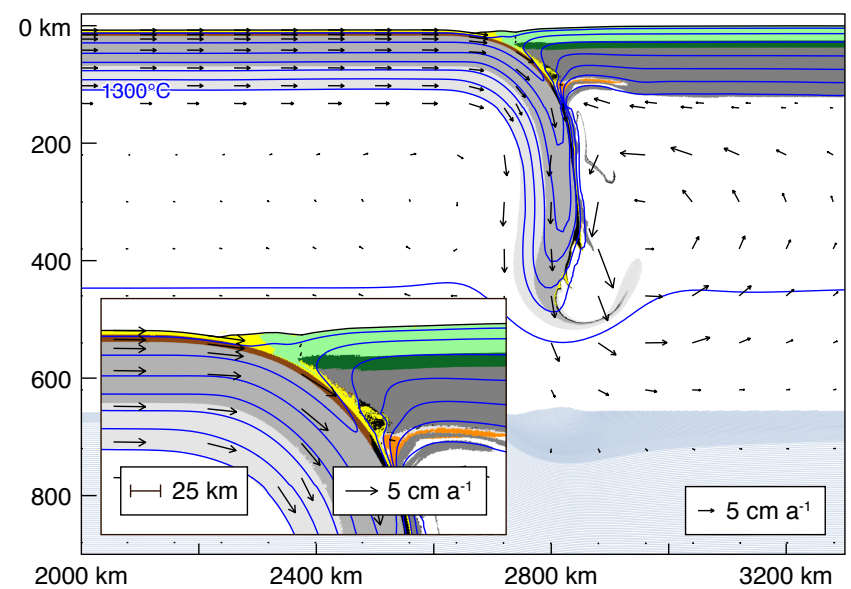

(c) Model FA-R; t $=12.0 \mathrm{Myr} ; \Delta x=600 \mathrm{~km}$

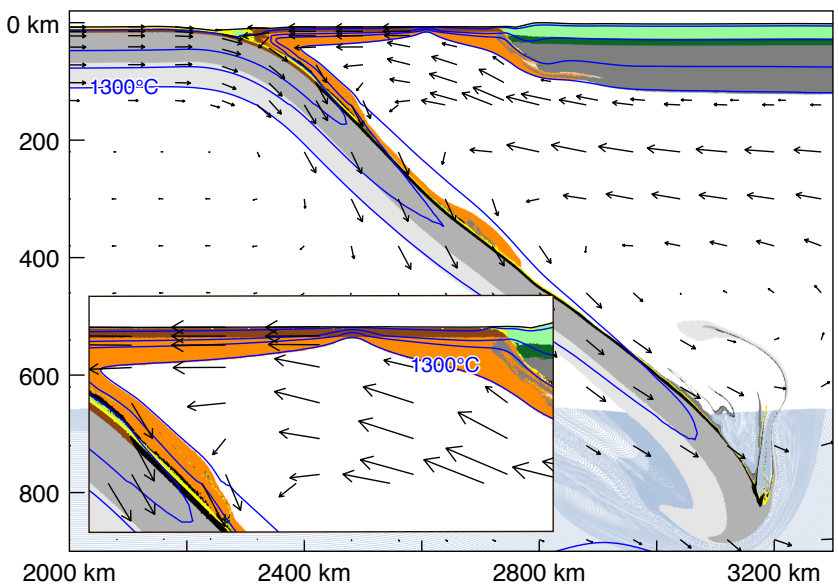

(e) Model FA-R; Tectonic forces

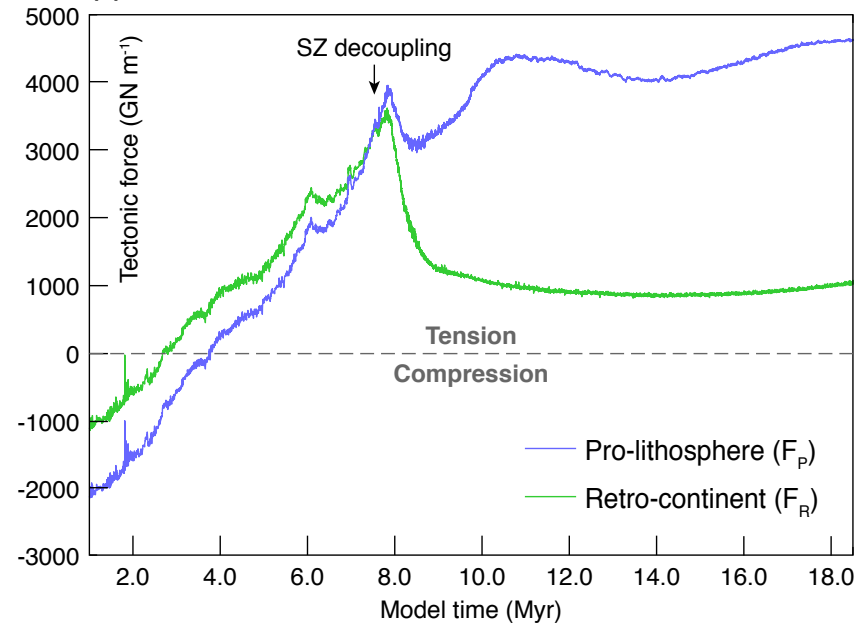

(b) Model FA-R; t $=8.5 \mathrm{Myr} ; \Delta x=425 \mathrm{~km}$

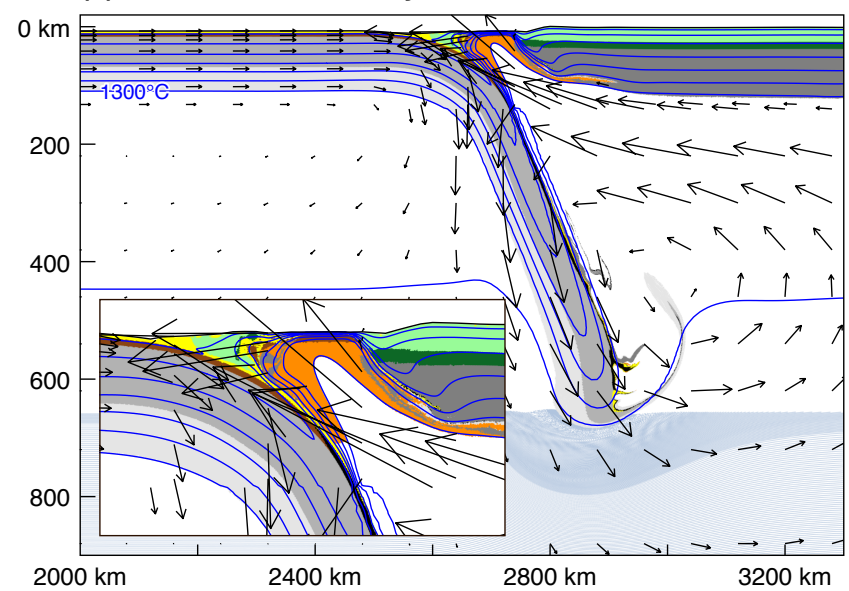

(d) Model FA-R; t $=18.5 \mathrm{Myr} ; \Delta x=925 \mathrm{~km}$

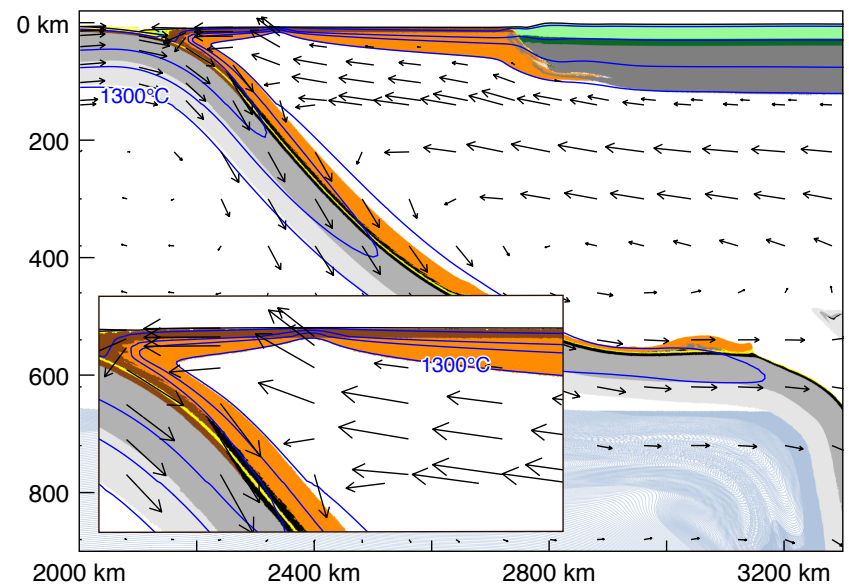

(f) Model FA-R; t = 8.5 Myr; inset enlarged

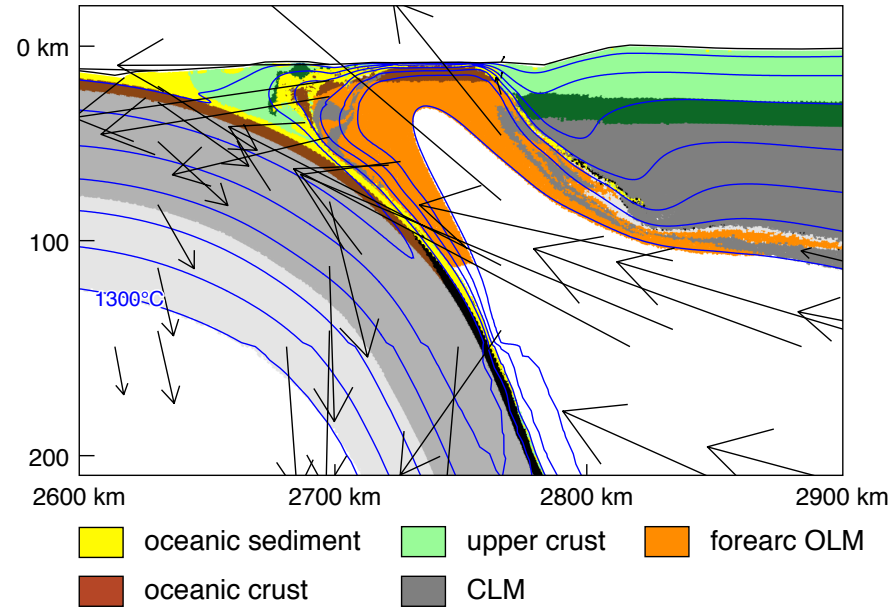


(a) Model FA-B-R; $t=6.5 \mathrm{Myr} ; \Delta x=325 \mathrm{~km}$

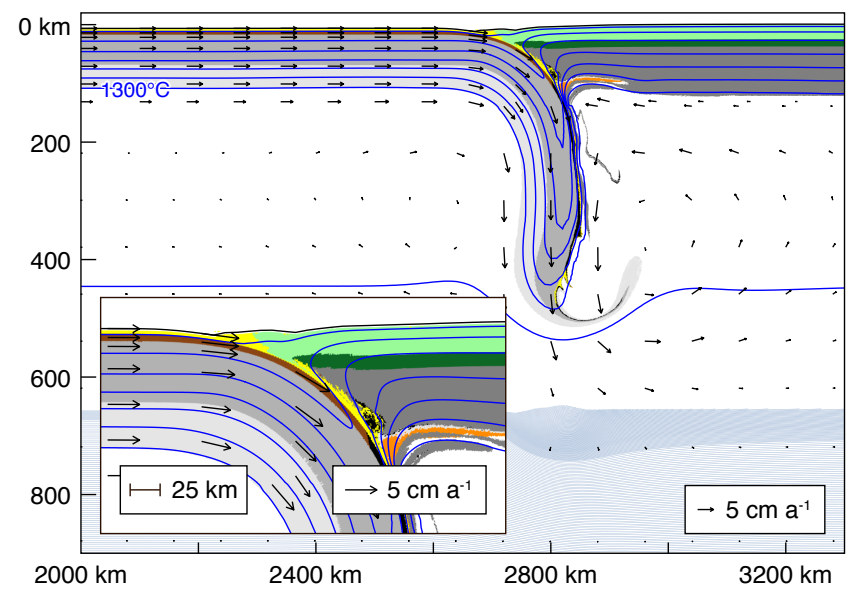

(c) Model FA-B-R; t $=16.5 \mathrm{Myr} ; \Delta \mathrm{x}=825 \mathrm{~km}$

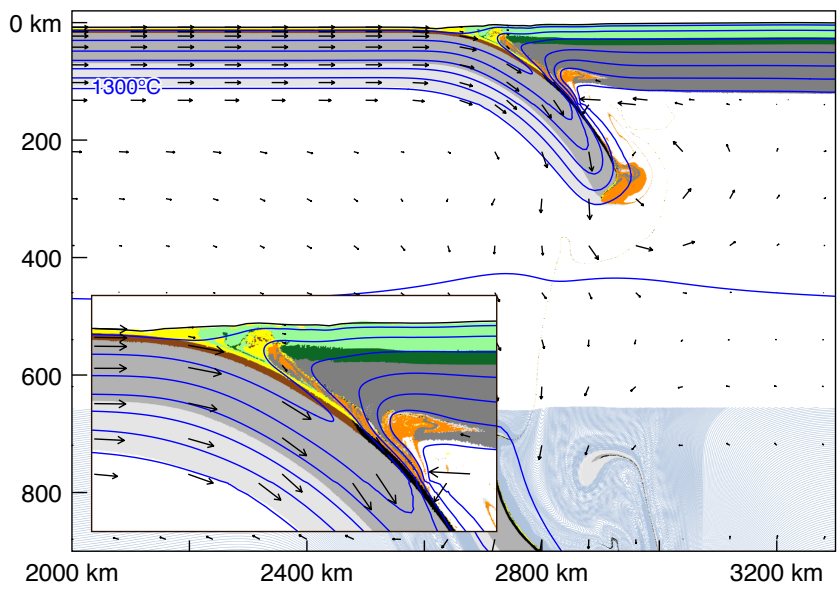

(e) Model FA-B-R; $t=27.5 \mathrm{Myr} ; \Delta x=1375 \mathrm{~km}$

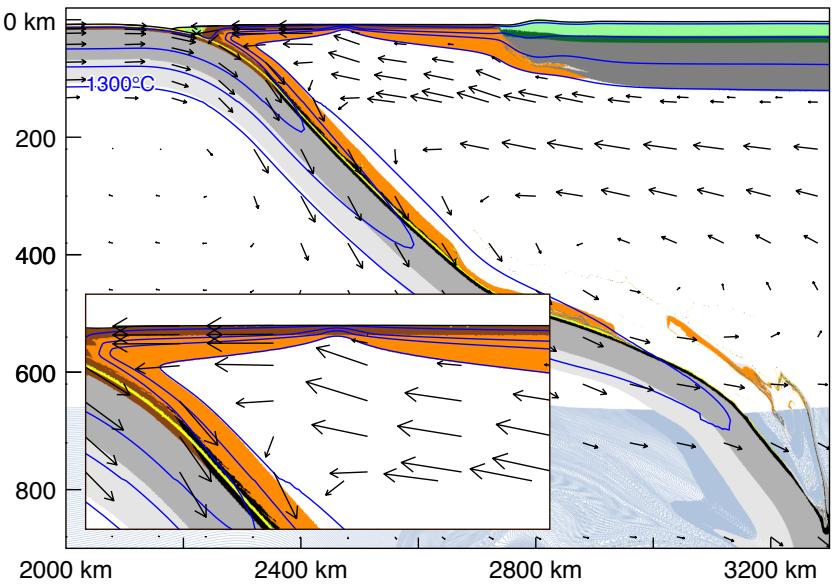

(b) Model FA-B-R; t $=10.5 \mathrm{Myr} ; \Delta \mathrm{x}=525 \mathrm{~km}$

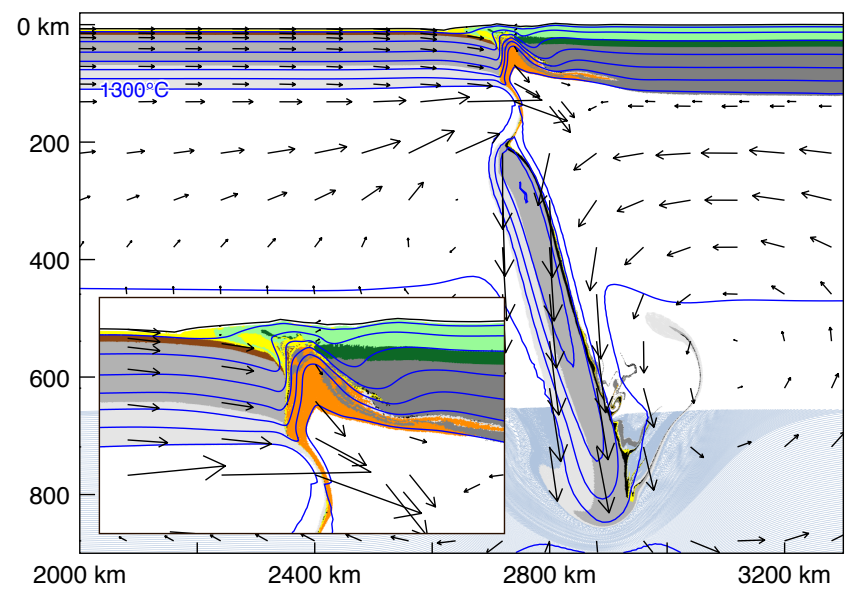

(d) Model FA-B-R; t = 21.0 Myr; $\Delta x=1050 \mathrm{~km}$

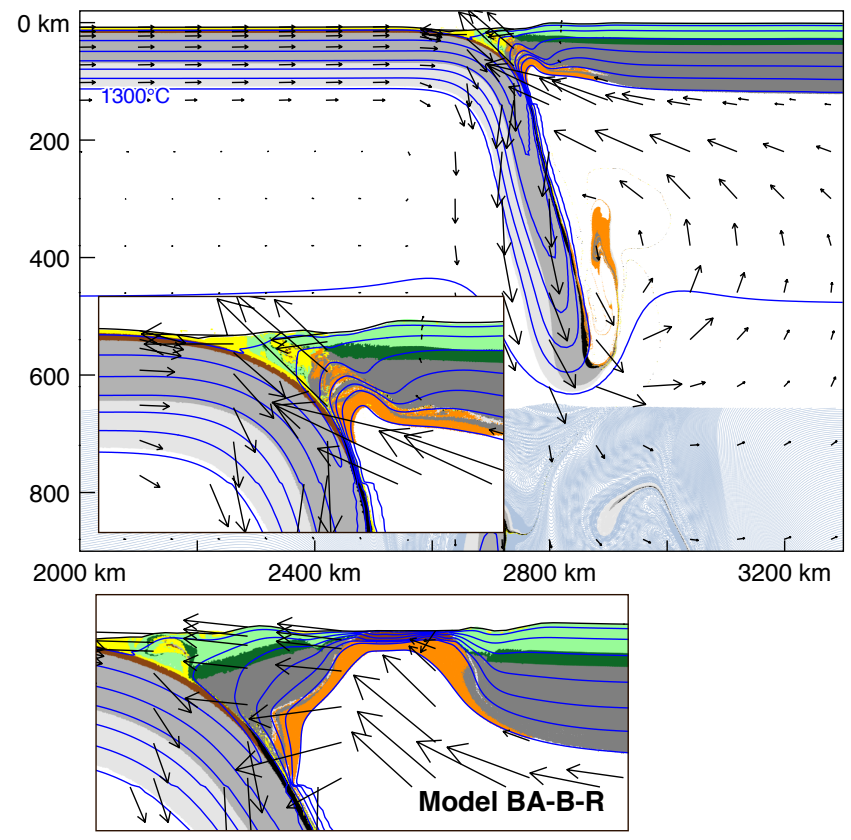

(f) Model FA-B-R; Tectonic forces

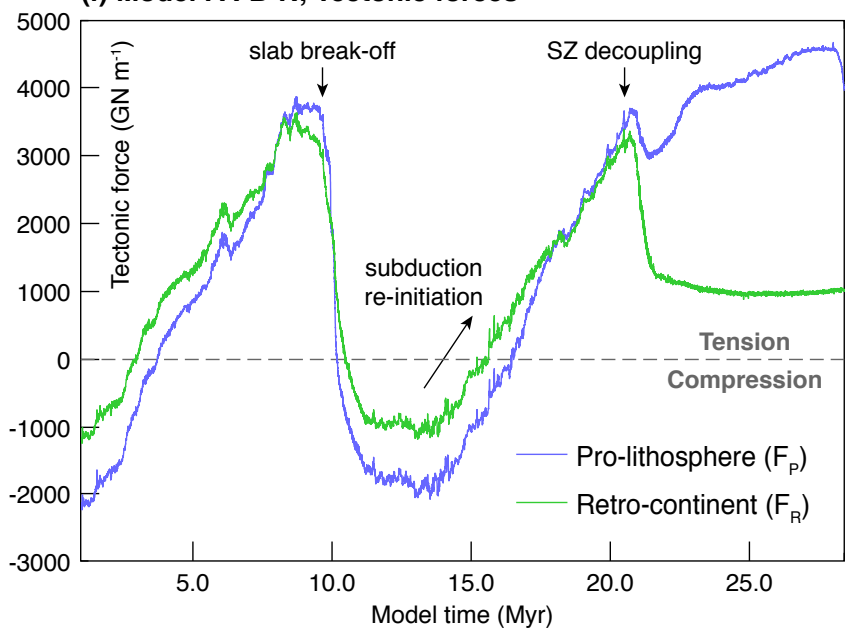


(a) 1. Model FA-R; $t=7.3 \mathrm{Myr}$; regions on yield

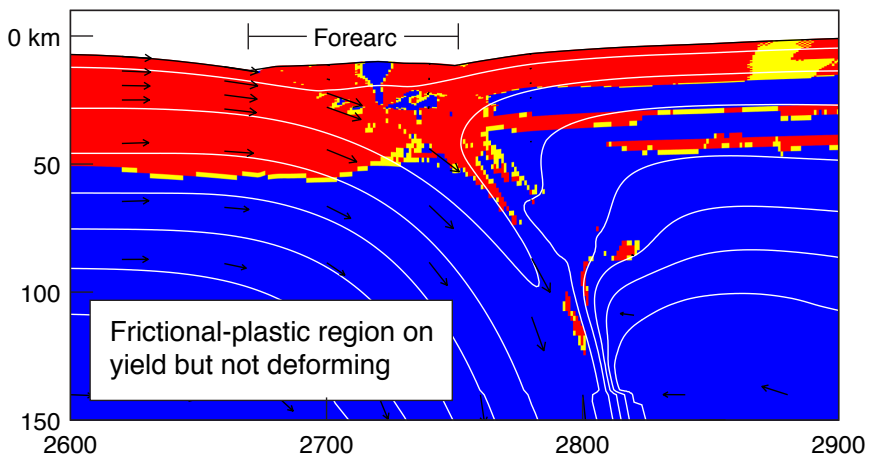

(c) 3. Model FA-R; t = 7.8 Myr; viscosity

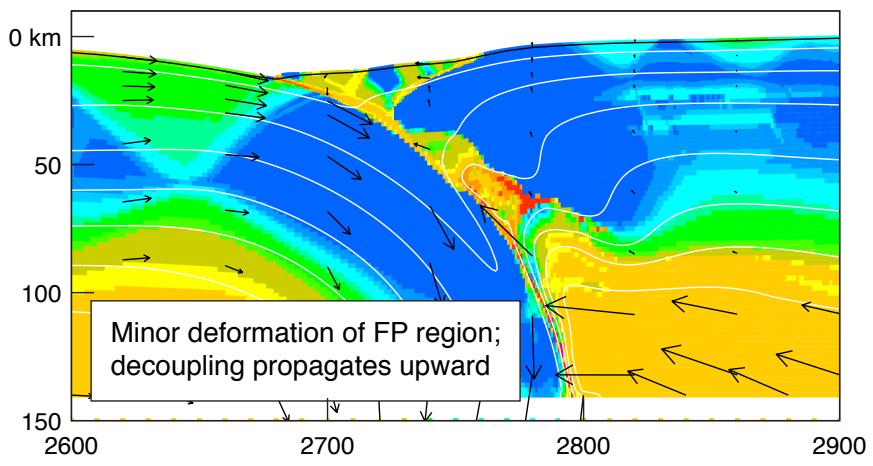

(e) 5. Model FA-R; $t=8.5$ Myr; viscosity

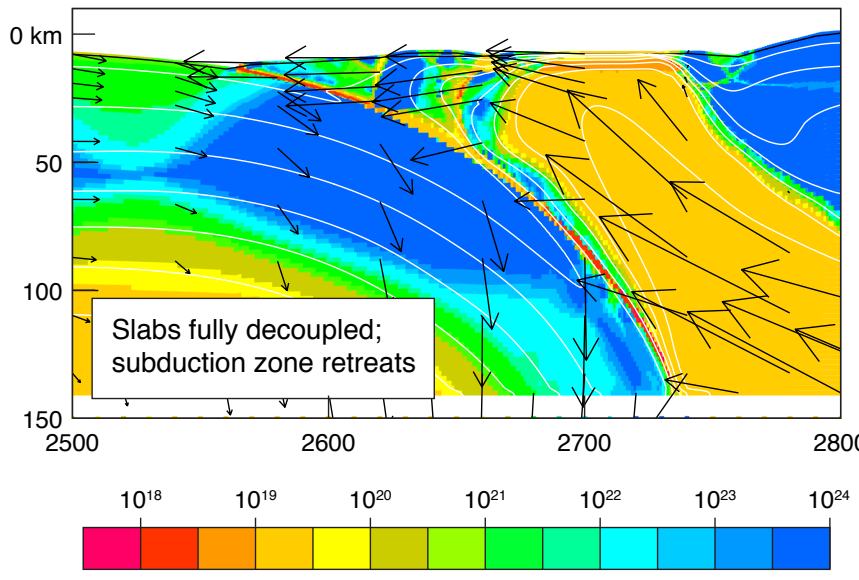

Effective viscosity ( $\eta \mathrm{Pa} \cdot \mathrm{s})$ (b) 2. Model FA-R; $t=7.4$ Myr; viscosity

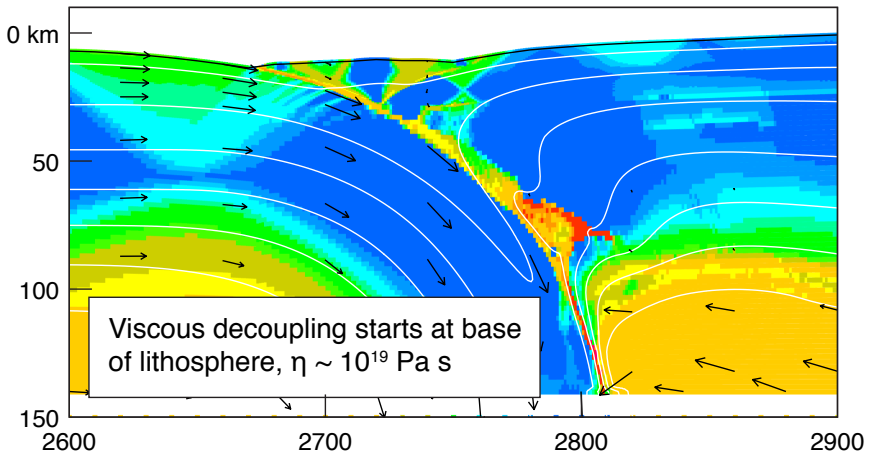

(d) 4. Model FA-R; $t=7.9$ Myr; viscosity

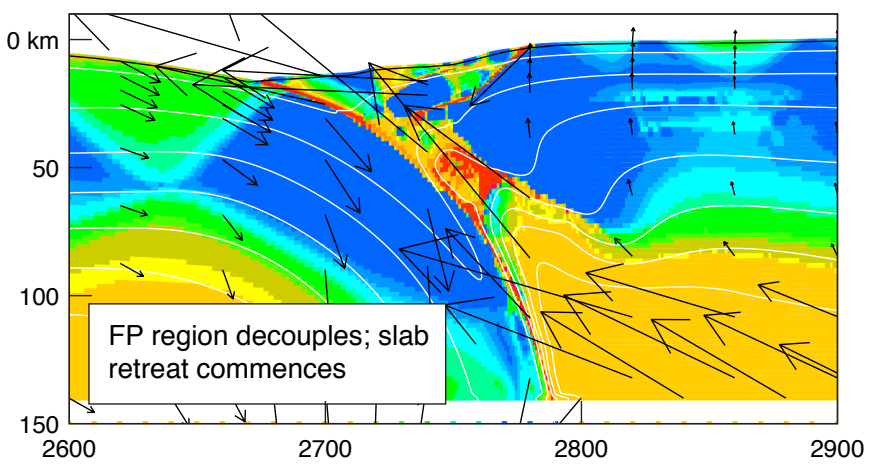

(f) Model FA-R; Tectonic forces

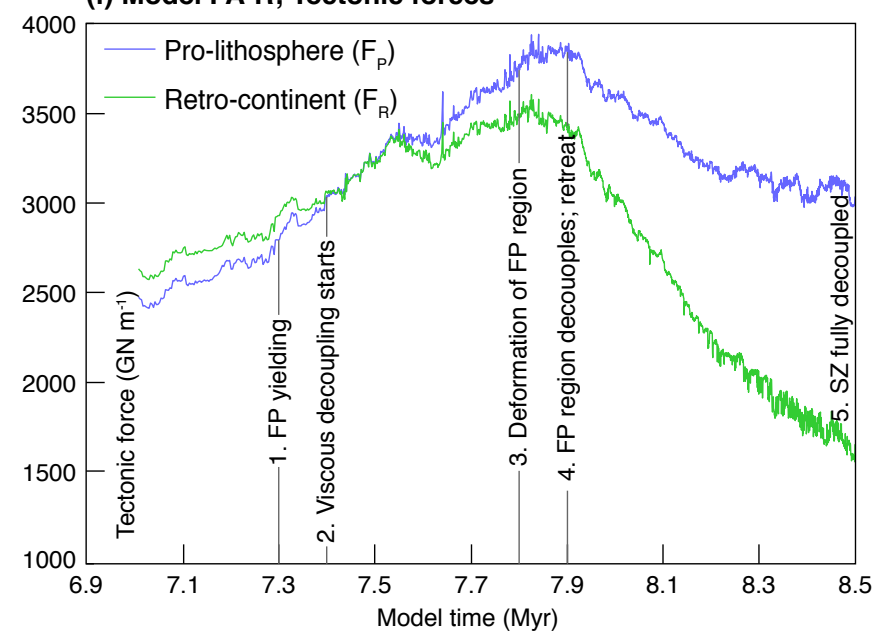


(a) Simplified timescale

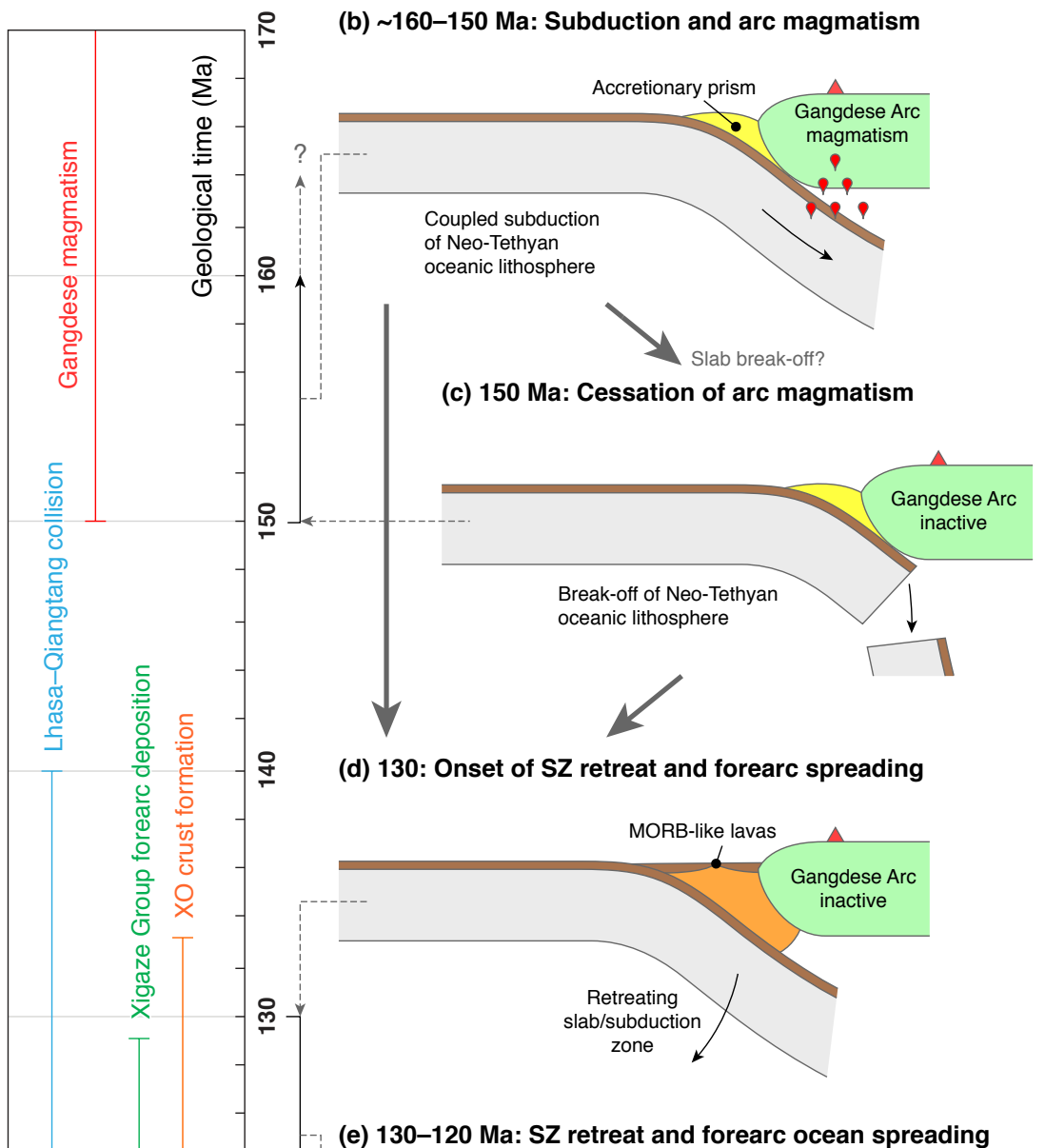

(e) 130-120 Ma: SZ retreat and forearc ocean spreading

Metamorphic sole Boninites MORB-like lavas

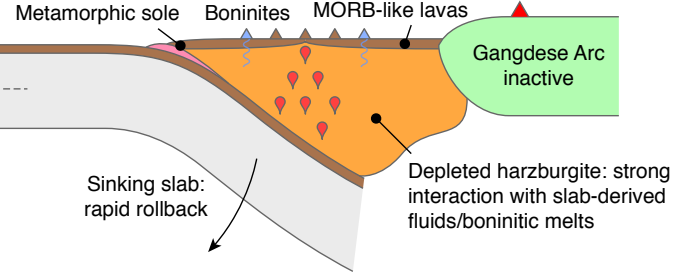

(f) 116-80 Ma: SZ advance/reactivation of arc

욷

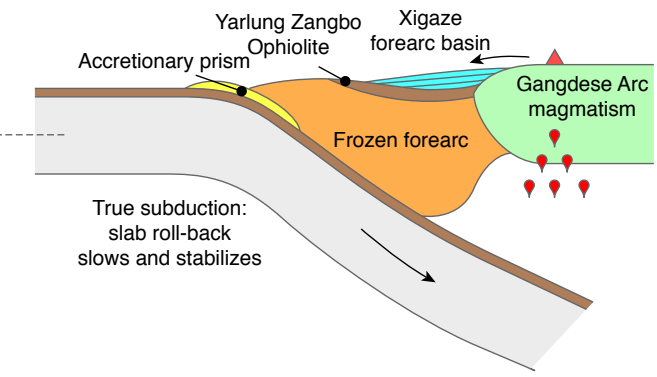

(g) Normal subduction

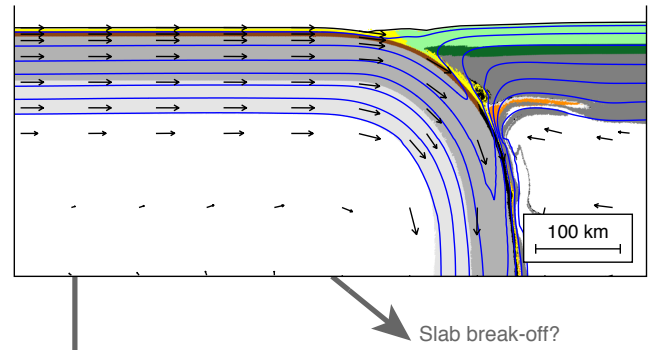

(h) Slab break-off

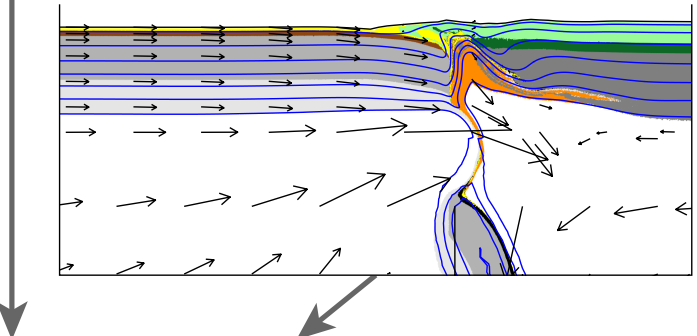

(i) Onset of SZ retreat

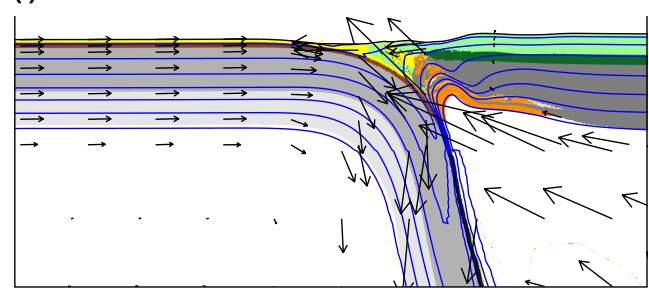

(j) SZ retreat and forearc ocean spreading

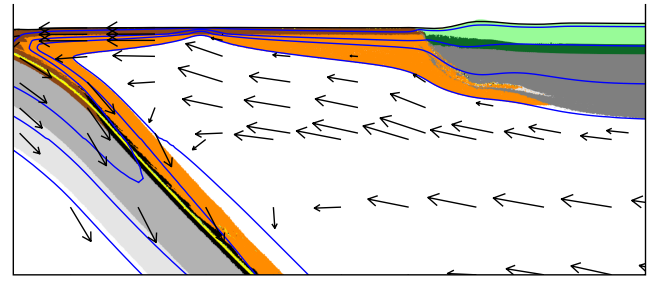


(a) Model FA-R-EX1; $\Delta t_{D}=3.0 \mathrm{Myr}$

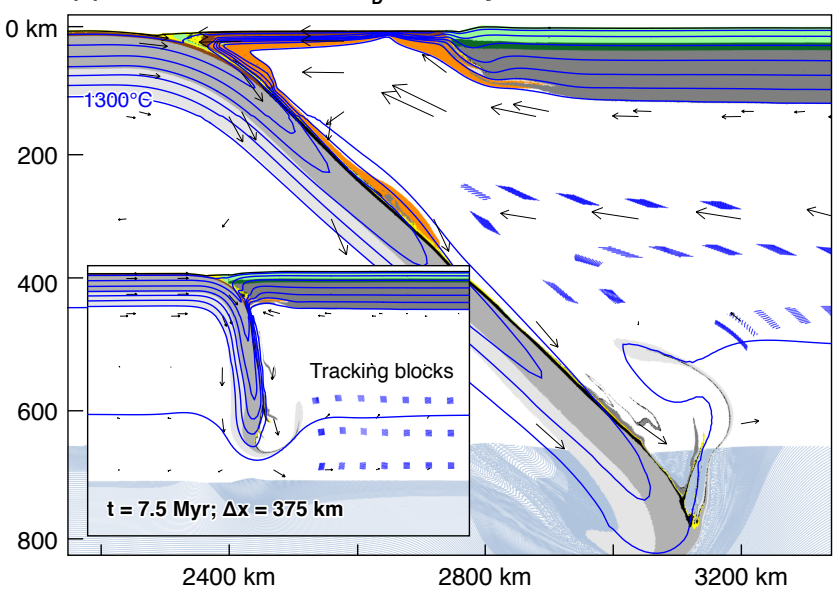

(b) Model FA-R-EX1; $\Delta t_{D}=6.0 \mathrm{Myr}$

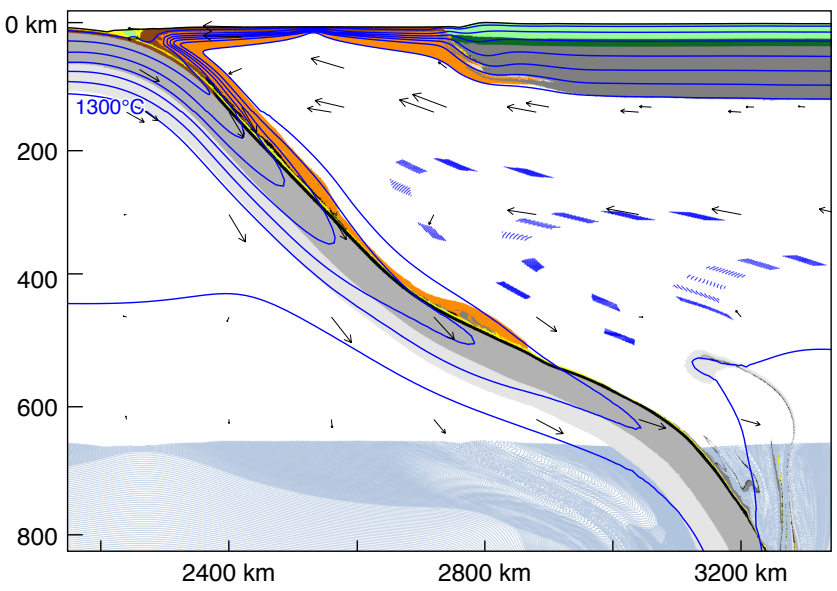

(c) Model FA-R-EX1; $\Delta t_{D}=6.0 \mathrm{Myr}$; max. pressure

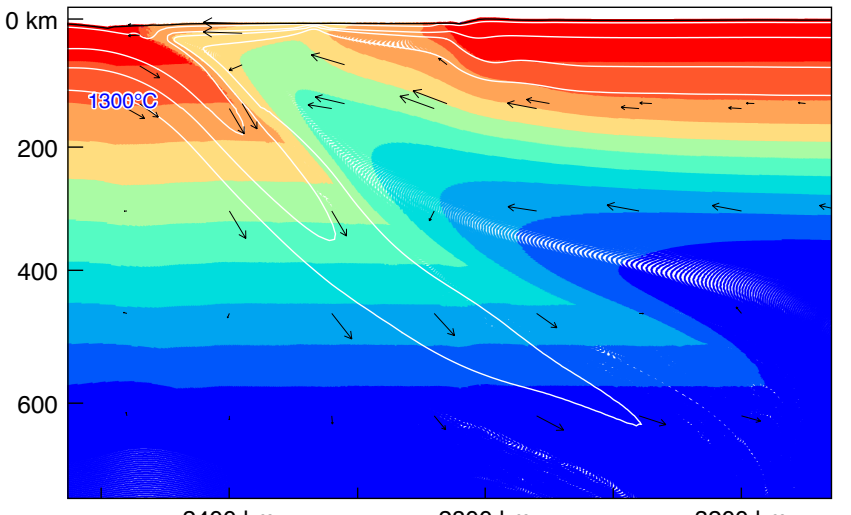

$2400 \mathrm{~km}$

$2800 \mathrm{~km}$

$3200 \mathrm{~km}$

$\begin{array}{lllllllllll}0 & 2 & 4 & 6 & 8 & 10 & 12 & 14 & 16 & 18 & 20\end{array}$ (d) Model FA-R-EX2; $\Delta t_{D}=1.0 \mathrm{Myr}$

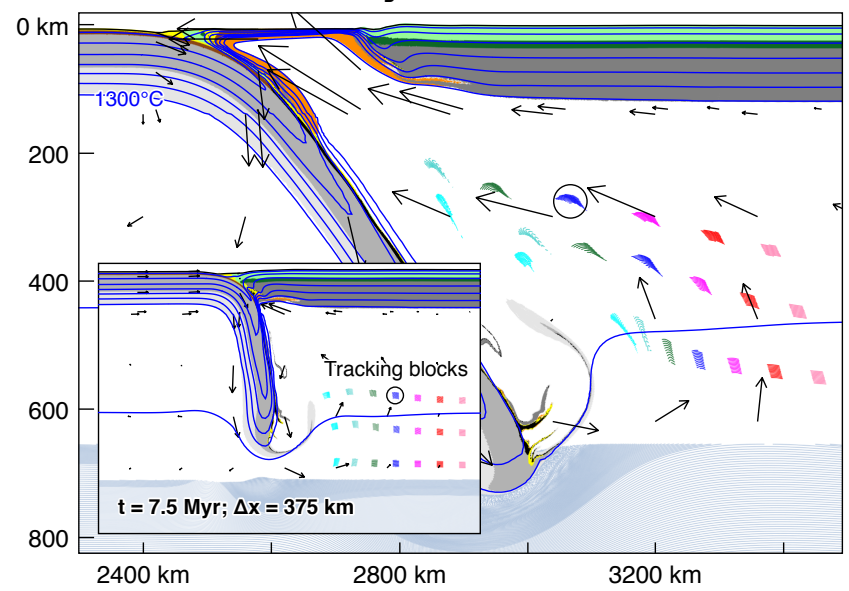

(e) Model FA-R-EX2; $\Delta t_{D}=6.0 \mathrm{Myr}$

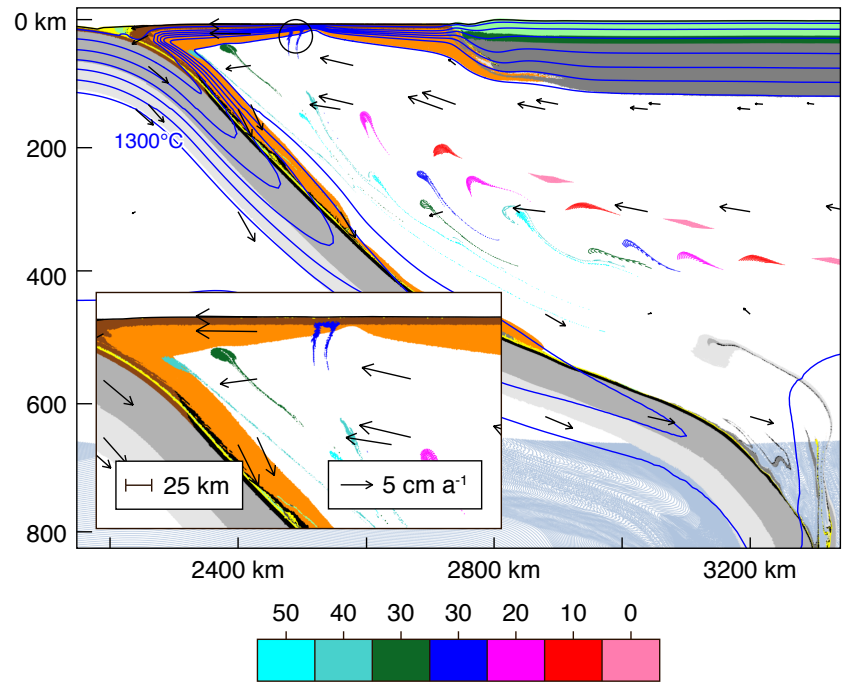

Depletion $\left(\Delta \rho ; \mathrm{kg} \mathrm{m}^{-3}\right)$

(f) Model FA-R-EX2; $\Delta \mathrm{t}_{\mathrm{D}}=6.0 \mathrm{Myr}$; max. pressure

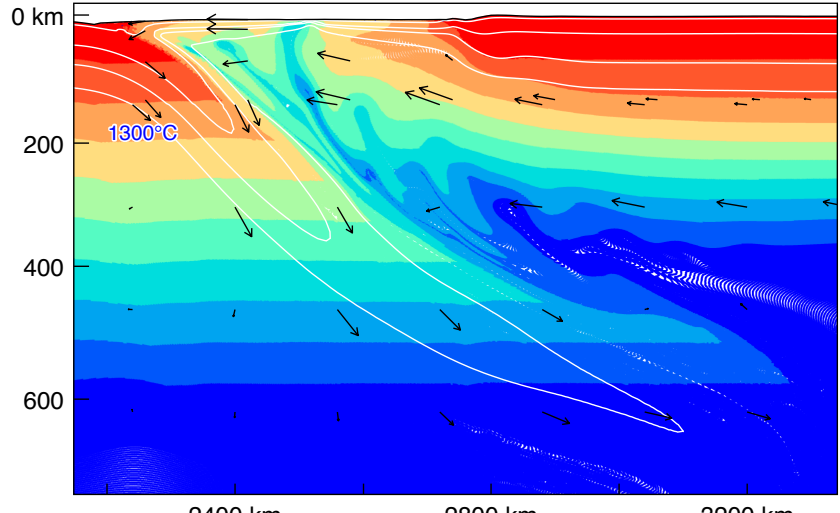

$2400 \mathrm{~km}$ 
Table 1

\begin{tabular}{|c|c|c|c|c|c|c|c|c|c|c|}
\hline & Units & Oceanic sediment & $\begin{array}{l}\text { Oceanic crust/forearc } \\
\text { oceanic crust }\end{array}$ & $\begin{array}{l}\text { RC (Retro-Continent) } \\
\text { upper crust }\end{array}$ & RC Lower crust & $\begin{array}{l}\mathrm{RC} \text { lithospheric } \\
\text { mantle }\end{array}$ & $\begin{array}{l}\text { Oceanic lithospheric } \\
\text { mantle }\end{array}$ & $\begin{array}{l}\text { Forearc oceanic } \\
\text { lithospheric mantle }\end{array}$ & $\begin{array}{l}\text { Sub-lithospheric } \\
\text { upper mantle }\end{array}$ & Lower mantle \\
\hline \multicolumn{11}{|l|}{$\begin{array}{l}\text { Mechanical } \\
\text { parameters }\end{array}$} \\
\hline Thickness (max.) & $\mathrm{km}$ & 3 & 6 & 24 & 12 & 84 & 91 & computed by model & to $660 \mathrm{~km} \mathrm{depth}$ & $660-1200 \mathrm{~km}$ depth \\
\hline $\begin{array}{l}\text { Reference } \\
\text { density }\left(0^{\circ} \mathrm{C}\right)\end{array}$ & $\mathrm{kg} \mathrm{m}^{-3}$ & 2800 & 2950 & 2800 & 2900 & 3340 & $\begin{array}{c}3370 \text { (variably } \\
\text { depletedk abovev } 60 \\
\text { km depth) }\end{array}$ & $\begin{array}{l}3370 \text { (3340 above } 60 \\
\text { km depth) }\end{array}$ & 3370 & 3630 \\
\hline $\begin{array}{l}\text { Reference } \\
\text { density HP } \\
\left(0^{\circ} \mathrm{C}\right)^{\mathrm{a}}\end{array}$ & $\mathrm{kg} \mathrm{m}^{-3}$ & 2900 & 3400 & 2900 & 3200 & No change & No change & No change & No change & No change \\
\hline $\begin{array}{l}\text { Reference } \\
\text { density UHP } \\
\left(0^{\circ}\right)^{\mathrm{a}}\end{array}$ & $\mathrm{kg} \mathrm{m}^{-3}$ & 3370 & No Change & 3000 & No Change & No change & $\begin{array}{l}\text { Changes to } 3630 \text { at } \\
660 \mathrm{~km} \text { depth }\end{array}$ & $\begin{array}{l}\text { Changes to } 3630 \text { at } \\
660 \mathrm{~km} \text { depth }\end{array}$ & $\begin{array}{l}\text { Changes to } 3630 \text { at } \\
660 \mathrm{~km} \text { depth }\end{array}$ & No change \\
\hline $\begin{array}{l}\text { Effective angle of } \\
\text { internal friction } \\
\left(\phi_{e f f}\right)^{\mathrm{h}}\end{array}$ & deg & $8-2$ & $15-2$ & $\begin{array}{c}15-2 \text { (8-2 in upper } 10 \\
\mathrm{~km})\end{array}$ & $15-2$ & $15-2$ & $15-2$ & $15-2$ & $15-2$ & $15-2$ \\
\hline Cohesion & $\mathrm{MPa}$ & 2 & 2 & 2 & 2 & 2 & 2 & 2 & 2 & 2 \\
\hline Flow law & - & WQ & DMD & WQ & DMD & WOL & WOL & WOL & WOL & $\begin{array}{l}\text { Constant viscosity } \\
1 \times 10^{21} \mathrm{~Pa} \mathrm{~s}\end{array}$ \\
\hline $\begin{array}{l}\text { Viscosity scaling } \\
\text { factor }(f)\end{array}$ & - & variable $^{b}$ & $0.1 \mathrm{i}$ & $5(1$ in upper $10 \mathrm{~km})$ & 0.5 & 10 & 3 & 3 & 2 & - \\
\hline $\begin{array}{l}\text { Strain } \\
\text { weakening } \\
\text { factor }\left(W_{s}\right)\end{array}$ & - & 1 & 10 & 10 & 10 & 1 & 1 & 1 & 1 & - \\
\hline $\mathrm{n}$ & - & 4 & 4.7 & 4 & 4.7 & 3 & 3 & 3 & 3 & - \\
\hline $\mathrm{A}^{\mathrm{c}}$ & $\mathrm{Pa}^{-1} \mathrm{~s}^{-1}$ & $8.57 \times 10^{-28}$ & $5.78 \times 10^{-27}$ & $8.57 \times 10^{-28}$ & $5.78 \times 10^{-27}$ & $1.76 \times 10^{-14}$ & $1.76 \times 10^{-14}$ & $1.76 \times 10^{-14}$ & $1.76 \times 10^{-14}$ & - \\
\hline$Q$ & $\mathrm{~kJ} \mathrm{~mol}{ }^{-1}$ & 223 & 485 & 223 & 485 & 430 & 430 & 430 & 430 & - \\
\hline $\mathrm{V}^{*}$ & $\mathrm{~m}^{3} \mathrm{~mol}^{-1}$ & 0 & 0 & 0 & 0 & $11 \times 10^{-6}$ & $11 \times 10^{-6}$ & $11 \times 10^{-6}$ & $11 \times 10^{-6}$ & - \\
\hline \multicolumn{11}{|l|}{$\begin{array}{l}\text { Thermal } \\
\text { parameters }\end{array}$} \\
\hline Specific heat & $\mathrm{m}^{2} \mathrm{~s}^{-2} \mathrm{~K}^{-1}$ & 750 & 750 & 750 & 750 & 1250 & 1250 & 1250 & 1250 & 1250 \\
\hline $\begin{array}{l}\text { Thermal } \\
\text { conductivity }\end{array}$ & 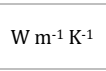 & 2.25 & $2.25^{i}$ & 2.25 & 2.25 & $5-2.4^{e}$ & $5-2.4^{\mathrm{e}}$ & $5-2.4^{\mathrm{e}}$ & $52.5^{\mathrm{f}}$ & $52.5^{\mathrm{f}}$ \\
\hline $\begin{array}{l}\text { Thermal } \\
\text { diffusivity }\end{array}$ & $\mathrm{m}^{2} \mathrm{~s}^{-1}$ & $1 \times 10^{-6}$ & $1 \times 10^{-6}$ & $1 \times 10^{-6}$ & $1 \times 10^{-6}$ & $1.3-0.64 \times 10^{-6 e}$ & $1.3-0.64 \times 10^{-6 e}$ & $1.3-0.64 \times 10^{-6 e}$ & $1.4 \times 10^{-5}$ & $1.4 \times 10^{-5}$ \\
\hline $\begin{array}{l}\text { Thermal } \\
\text { expansion } \\
\text { coefficient }\end{array}$ & $\mathrm{K}^{-1}$ & $3 \times 10^{-5}$ & $3 \times 10^{-5}$ & $3 \times 10^{-5}$ & $3 \times 10^{-5}$ & $3.2-3.9 \times 10^{-5 g}$ & $3.2-3.9 \times 10^{-5 g}$ & $3.2-3.9 \times 10^{-5 g}$ & $3.2-3.9 \times 10^{-5 g}$ & $3.2-3.9 \times 10^{-5 g}$ \\
\hline $\begin{array}{l}\text { Radioactive heat } \\
\text { production }\left(\mathrm{A}_{\mathrm{R}}\right)\end{array}$ & $\mu \mathrm{W} \mathrm{m}^{-3}$ & 1 & 0 & 1.5 & 0.4 & 0 & 0 & 0 & 0 & 0 \\
\hline \multicolumn{11}{|c|}{ 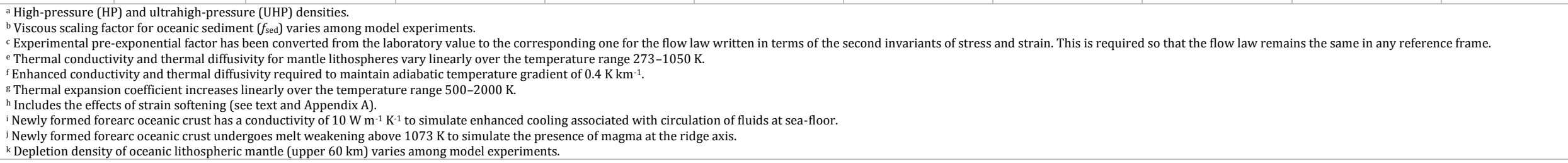 } \\
\hline
\end{tabular}

